\title{
Two Novel MvaT-Like Global Regulators Control Exoproduct Formation and Biocontrol Activity in Root-Associated Pseudomonas fluorescens CHAO
}

\author{
Eric Baehler, ${ }^{1}$ Patrice de Werra, ${ }^{1}$ Lukas Y. Wick, ${ }^{2}$ Maria Péchy-Tarr, ${ }^{1}$ Sophie Mathys, ${ }^{1}$ \\ Monika Maurhofer, ${ }^{3}$ and Christoph Keel ${ }^{1}$ \\ ${ }^{1}$ Department of Fundamental Microbiology, University of Lausanne, $\mathrm{CH}-1015$ Lausanne, Switzerland; ${ }^{2}$ Department \\ of Environmental Microbiology, Centre for Environmental Research (GmbH), UFZ, D-04318 Leipzig, Germany; \\ ${ }^{3}$ Phytopathology group, Institute of Plant Sciences, Swiss Federal Institute of Technology (ETH), CH-8092 Zurich, \\ Switzerland
}

Submitted 24 May 2005. Accepted 24 October 2005.

Pseudomonas fluorescens CHA0 protects various crop plants against root diseases caused by pathogenic fungi. Among a range of exoproducts excreted by strain CHA0, the antifungal compounds 2,4-diacetylphloroglucinol (DAPG) and pyoluteorin (PLT) are particularly relevant to the strain's biocontrol potential. Here, we report on the characterization of MvaT and MvaV as novel regulators of biocontrol activity in strain CHAO. We establish the two proteins as further members of an emerging family of MvaT-like regulators in pseudomonads that are structurally and functionally related to the DNA-binding protein H-NS. In mvaT and mvaV in frame-deletion mutants of strain CHA0, PLT production was enhanced about fourand 1.5-fold, respectively, whereas DAPG production remained at wild-type levels. Remarkably, PLT production was increased up to 20 -fold in an mvaT mvaV double mutant. DAPG biosynthesis was almost completely repressed in this mutant. The effects on antibiotic production could be confirmed by following expression of $g f p$-based reporter fusions to the corresponding biosynthetic genes. MvaT and MvaV also influenced levels of other exoproducts, motility, and physicochemical cell-surface properties to various extents. Compared with the wild type, mvaT and mvaV mutants had an about $20 \%$ reduced capacity (in terms of plant fresh weight) to protect cucumber from a root rot caused by Pythium ultimum. Biocontrol activity was nearly completely abolished in the double mutant. Our findings indicate that MvaT and MvaV act together as further global regulatory elements in the complex network controlling expression of biocontrol traits in plant-beneficial pseudomonads.

Corresponding author: C. Keel; Telephone: +41 2169256 36; Fax: +41 2169256 05; E-mail: christoph.keel@unil.ch

Current address of P. de Werra: Institut für Pflanzenwissenschaften/Phytopathologie, Eidgenössische Technische Hochschule (ETH), CH-8092 Zürich, Switzerland.

Current address of S. Mathys: Institut für Lebensmittel- und Ernährungswissenschaften, Eidgenössische Technische Hochschule (ETH), CH-8092 Zürich, Switzerland.

Nucleotide and amino acid sequence data reported are available in the GenBank and EMBL databases under accession numbers AY922310 and AY922311.
Additional keywords: biosurfactants, exoenzymes, hydrogen cyanide, rhizosphere.

Soil-borne pathogenic fungi and oomycetes, among them members of the genera Rhizoctonia, Fusarium, Thielaviopsis, Gaeumannomyces, Phomopsis, Aphanomyces, and Pythium, attack plant roots and cause considerable damage to field- and greenhouse-grown crops worldwide. Particular strains of fluorescent pseudomonads that effectively colonize the roots can protect the plants from attack by these pathogens (Haas and Défago 2005). Disease suppression brought about by plantbeneficial pseudomonads involves a blend of possible mechanisms and relies on complex, often subtle interactions between the bacterial antagonist, the pathogen, and the host plant (Haas and Défago 2005). Rhizosphere competence is an essential prerequisite for biocontrol efficacy of fluorescent pseudomonads and depends on traits that allow effective root colonization and competition for nutrients and niches (Chin-A-Woeng et al. 2003; Lugtenberg et al. 2001). Direct antagonism against the pathogen by production of diffusible or volatile antimicrobial compounds or by inactivation of virulence traits is a primary mechanism of biocontrol (Chin-A-Woeng et al. 2003; Haas and Défago 2005; Haas and Keel 2003). Indirect inhibition of the pathogen by bacterial stimulation of defense responses in the host plant is another major biocontrol mechanism (Van Loon and Bakker 2004). Plant-beneficial pseudomonads release a remarkable diversity of exoproducts with antimicrobial, metalchelating, lytic, and phytohormonal activity, and some of them have a determinative role in disease suppression (Chin-AWoeng et al. 2003; Haas and Défago 2005; Haas and Keel 2003).

In our studies, we make use of Pseudomonas fluorescens $\mathrm{CHA}$, a root-associated beneficial bacterium that displays a broad spectrum of biocontrol activity against some of the major soil-borne plant pathogens on various mono- and dicotyledonous crop plants (Keel and Défago 1997). In the course of the past 15 years, $P$. fluorescens $\mathrm{CHA} 0$ has evolved as an important model organism for studies into the regulatory mechanisms governing biocontrol activity. Strain CHA0 produces the two potent antifungal compounds pyoluteorin (PLT) and 2,4-diacetylphloroglucinol (DAPG) that are major determinants of its disease suppressive capacity (Keel et al. 1992; Maurhofer et al. 1992, 1994). A series of other metabolites, including hydrogen 
cyanide $(\mathrm{HCN})$, pyrrolnitrin, and siderophores, and certain extracellular enzymes may add to the strain's biocontrol potential as well (Haas and Keel 2003; Keel and Défago 1997; Voisard et al. 1989, 1994). The biosynthetic loci for DAGP and PLT have been identified and studied in some detail in strain CHA0 and several other biocontrol pseudomonads. They are organized as clusters and comprise the phlACBD (for DAPG) and the pltLABCDEFG (for PLT) genes that are preceded by the divergently transcribed $p h l F$ and $p l t R$ genes, respectively, encoding pathway-specific transcriptional regulators (Abbas et al. 2002; Bangera and Thomashow 1999; Haas and Keel 2003; Nowak-Thompson et al. 1999; Péchy-Tarr et al. 2005; Schnider-Keel et al. 2000).

Regulation of DAPG and PLT biosynthesis is complex and involves several levels of pathway-specific and global control. At a transcriptional level, DAPG and PLT positively control the expression of their own biosynthetic genes via the pathway-specific regulators $\mathrm{PhlF}$ and PltR, respectively (Abbas et al. 2002; Baehler et al. 2005; Brodhagen et al. 2004; Maurhofer et al. 2004; Schnider-Keel et al. 2000). Remarkably, DAPG strongly represses PLT biosynthesis and vice versa, pointing to a mechanism of mutual feedback control that may help $P$. fluorescens to keep production of these compounds at balanced levels (Baehler et al. 2005; Brodhagen et al. 2004; SchniderKeel et al. 2000). An additional level of transcriptional control of DAPG and PLT gene expression is provided by the housekeeping sigma factor RpoD (Schnider et al. 1995), the stress and stationary phase sigma factor RpoS (Haas and Keel 2003; Sarniguet et al. 1995), as well as by RpoN, a sigma factor involved in the control of motility and catabolism of various carbon and nitrogen sources (Péchy-Tarr et al. 2005). In addition, biosyntheses of DAPG, PLT, and a series of other exoproducts are positively controlled by the GacS/GacA two-component system via a regulatory cascade in which the response regulator GacA promotes the transcription of small regulatory RNAs termed RsmX, RsmY, and RsmZ, which interfere with the negative effects of translational repressors (RsmA, RsmE) of biocontrol gene expression (Haas and Défago 2005). A further level of complexity is added by the effects of numerous biotic and abiotic environmental signals, e.g., certain micro- and macronutrients (Duffy and Défago 1999) and metabolites of microbial and plant origin (Baehler et al. 2005; Maurhofer et al. 2004; Notz et al. 2001; Schnider-Keel et al. 2000) that may have a considerable impact on phl and plt gene expression.

Recently, we have developed a set of reporter fusions to the DAPG and PLT biosynthetic genes that are based on variants of the green fluorescent protein (GFP) (Baehler et al. 2005). In the present study, we have used one of the constructs expressing a $p l t A-g f p$ fusion to screen for potential novel regulators of antifungal gene expression in P. fluorescens $\mathrm{CHA0}$. We report on the detection and characterization of two such regulators, which we termed MvaT and MvaV. We provide evidence that these proteins constitute two novel members of an emerging family of MvaT-like regulators in Pseudomonas species (Tendeng et al. 2003). MvaT was originally described by Rosenthal and Rodwell (1998) as a transcriptional regulator of the $m v a A B$ operon encoding enzymes involved in mevalonate catabolism in Pseudomonas mevalonii. Genomic analyses indicate the occurrence of MvaT-like proteins in numerous Pseudomonas species (Tendeng and Bertin 2003; Tendeng et al. 2003), but so far, only few studies have dealt with the functional roles of these proteins. In Pseudomonas aeruginosa, MvaT is an important global regulator of virulence gene expression and biofilm formation (Diggle et al. 2002; Vallet et al. 2004; Westfall et al. 2004). In Pseudomonas putida, an MvaT homolog named TurA contributes to modulation of the $P u$ promoter of the TOL plasmid (Rescalli et al. 2004). Excitingly, there is increasing evidence that MvaT-like proteins may be functionally and structurally related to H-NS, a nucleoid-associated protein that is widespread in gram-negative bacteria and has been extensively studied in Escherichia coli (Dame et al. 2005; Rescalli et al. 2004; Tendeng and Bertin 2003; Tendeng et al. 2003; Vallet et al. 2004). H-NS acts mainly as a repressor of transcription exerting its effects on hundreds of genes, many of them related to virulence functions and environmental adaptation (Atlung and Ingmer 1997; Dorman 2004; Hommais et al. 2001; Rimsky 2004; Tendeng and Bertin 2003). Here, we illustrate that MvaT and $\mathrm{MvaV}$ of $P$. fluorescens $\mathrm{CHA} 0$ are functionally related to $\mathrm{H}-\mathrm{NS}$, as they were able to restore $\mathrm{H}-$ NS-dependent phenotypes in an hns mutant of E. coli. We demonstrate that in frame-deletion mutations in mvaT and mvaV of strain CHA0 affect the balance of DAPG and PLT production, formation of several other exoproducts, motility, and certain cell-surface characteristics, and that these effects in general are more pronounced in an mvaT mvaV double mutant. Finally, we show that loss of MvaT and MvaV function in strain CHA0 entails a strongly reduced protection of cucumber plants against a root rot caused by Pythium ultimum, thus establishing members of the MvaT protein family for the first time as important regulators of biocontrol capacity in plant-associated pseudomonads.

\section{RESULTS}

\section{Identification and characterization of the chromosome regions containing mvaT and mvaV in P. fluorescens CHAO.}

In an approach to identify novel regulators of antibiotic production in $P$. fluorescens, we subjected a reporter strain, i.e., the rpoN mutant CHA250 (Péchy-Tarr et al. 2005) carrying a $p l t A-g f p$ fusion on pME7109 (Baehler et al. 2005), to a random Tn 5 insertion mutagenesis. Expression of pltA is strongly repressed in the rpoN mutant (Péchy-Tarr et al. 2005). The collection of Tn 5 insertion mutants generated was then screened for strains that were at least partly insensitive to down-regulation of pltA-gfp expression caused by the lack of RpoN. Among the 3,500 mutants tested, nine mutants attained levels of pltA expression that were at least 1.5-fold higher than those in the parental strain. The Tn5-flanking regions were amplified by arbitrary polymerase chain reaction (PCR), and were cloned and sequenced. Sequence analysis revealed that in one of the mutants, i.e., CHAMS4 (Fig. 1A; Table 1), the transposon had been inserted in a locus that was highly similar to the mvaT genes of $P$. mevalonii and $P$. aeruginosa (Diggle et al. 2002; Rosenthal and Rodwell 1998; discussed below). Compared with the rpoN mutant CHA250, the expression of the pltA-gfp reporter fusion was 2.2 to threefold enhanced in CHAMS4, reaching about $40 \%$ of the wild-type levels of pltA expression (data not shown). These findings could be confirmed in follow-up experiments (data not shown) with CHA1122, a derivative of CHA250 in which mvaT was deleted in frame by gene replacement (Table 1).

We then used sequence information available from the closely related strain P. fluorescens Pf-5 (Paulsen et al. 2005) to PCR-amplify, clone, and sequence a 2,251-bp chromosomal region in strain $\mathrm{CHA} 0$ containing mvaT and its surroundings (Fig. 1A). The deduced product (124 amino acids) of the mvaT gene of strain CHA0 is very similar to the P16 subunit of the $P$. mevalonii heterodimeric transcriptional regulator MvaT (GenBank accession number AAC46083; Rosenthal and Rodwell $1998 ; 86 \%$ identity), to the transcriptional regulator MvaT (annotated as PA4315) of $P$. aeruginosa PAO1 (Diggle et al. 2002; $77 \%$ identity), and to the TOL upper operon repressor TurA, an MvaT homolog (annotated as PP1366) of P. putida KT2440 
(Rescalli et al. 2004; 90\% identity). As in P. aeruginosa PAO1, the mvaT gene of $P$. fluorescens CHA0 is located between two divergently oriented open reading frames (ORF), encoding a putative formyltetrahydrofolate deformylase (ORFA, N-terminus $81 \%$ identical to PA4314) and a putative exodeoxyribonuclease I (ORFB, C-terminus 63\% identical to PA4316). This gene arrangement appears to be conserved also in other Pseudomonas species (data not shown).
Further examination of the available genomic data of $P$. fluorescens Pf-5 indicated the existence of a homolog of MvaT. We have used this information to amplify by PCR the corresponding region from the chromosome of $P$. fluorescens CHA0. Sequence analysis revealed the presence of an ORF encoding a protein (125 amino acids) that is $47 \%$ identical to MvaT of strain CHA0. By analogy with mvaT, we termed the novel ORF mvaV (Fig. 1B). MvaV shares 68\% identical amino

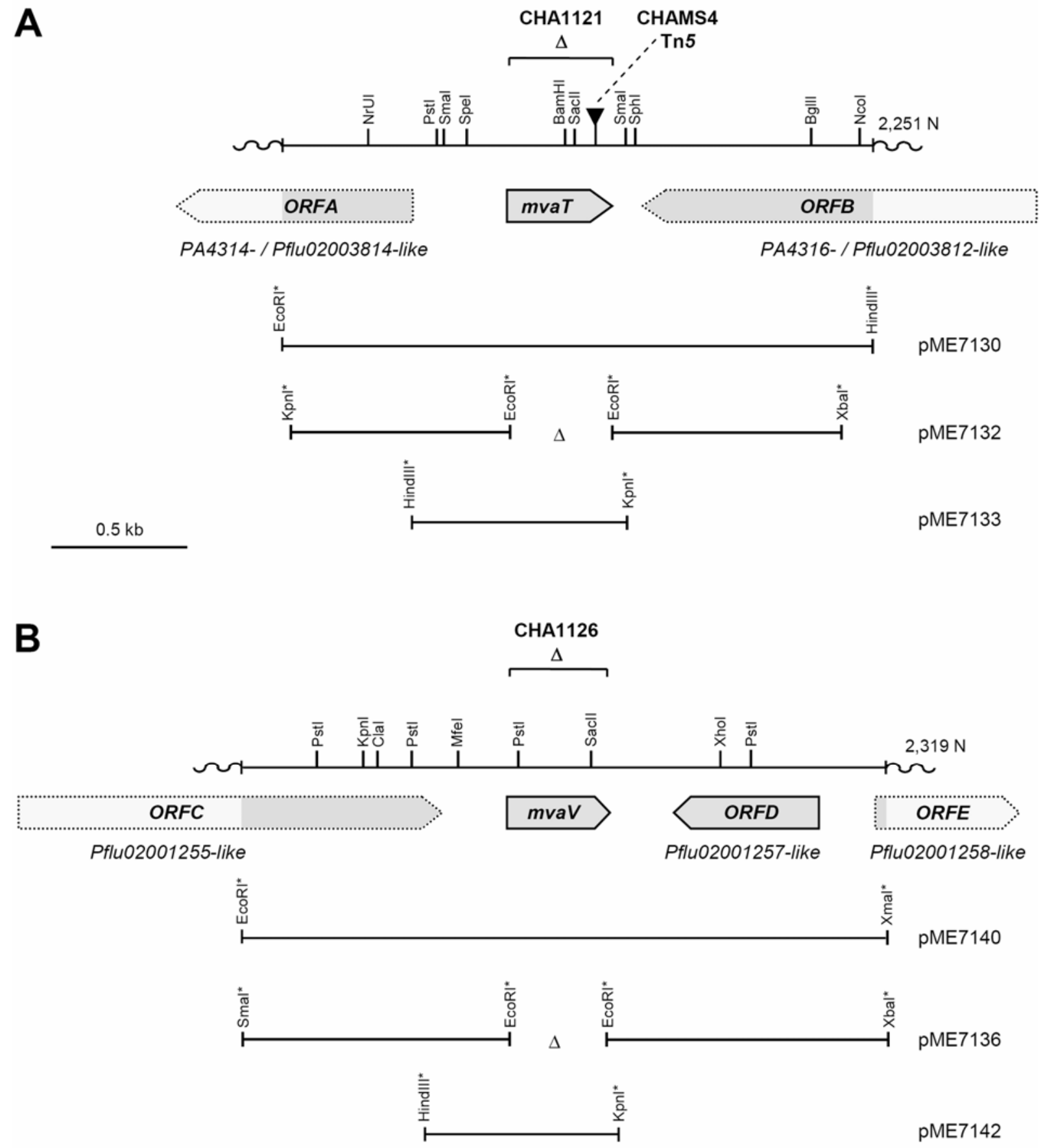

Fig. 1. Physical location of the A, mvaT and B, mvaV genes in Pseudomonas fluorescens strain CHA0. $\boldsymbol{\nabla}=$ Tn 5 insertion in the chromosome of strain CHAMS4; $\triangle$ = regions deleted in strains CHA1121 and CHA1126 and in plasmids pME7132 and pME7136. The shaded arrows show the genes sequenced or partly sequenced on the EcoRI-HindIII and EcoRI-XmaI fragments of pME7130 and pME7140, respectively. ORFA, ORFB, ORFC, ORFD, and ORFE designate open reading frames that are similar to Pflu02003814, Pflu02003812, Pflu02001255, Pflu02001257, and Pflu02001258, respectively, of $P$. fluorescens Pf0-1 (GenBank accession number AAAT03000000; Microbial Genomics website). ORFA and ORFB also are highly similar to PA4314 and PA4316, respectively, of $P$. aeruginosa PAO1 (GenBank accession number AE004091; Stover et al. 2000). The bars designate the fragments cloned into the vector pUK21 to give pME7130 and pME7140, into pME3087 to give pME7132 and pME7136, and into pME6182 to give pME7133 and pME7142. The fragments inserted in pME7133 and pME7142 were used to complement the mvaT mutation in CHA1121 and the mvaV mutation in CHA1126 with single-copy mvaT and $\mathrm{mvaV}^{+}$, respectively, using the mini-Tn7 delivery system. Artificial restriction sites are marked with an asterisk. 
Table 1. Bacterial strains, plasmids, and oligonucleotides used in this study

\begin{tabular}{|c|c|c|}
\hline Name & Relevant characteristics ${ }^{\mathrm{y}}$ or sequence $\left(5^{\prime} \rightarrow 3^{\prime}\right)^{\mathrm{z}}$ & Reference or source \\
\hline \multicolumn{3}{|l|}{ Pseudomonas fluorescens } \\
\hline CHAO & Wild type & Voisard et al. 1994 \\
\hline CHA0- $g$ & CHA0::att $\mathrm{Tn} 7-g f p 1 ; \mathrm{Km}^{\mathrm{r}}$ & NERI, Roskilde, Denmark \\
\hline CHA250 & $\Delta r p o N$ & Péchy-Tarr et al. 2005 \\
\hline CHA631 & $\Delta p h l A$ & Schnider-Keel et al. 2000 \\
\hline CHA661 & pltC::Tn5; $\mathrm{Km}^{\mathrm{r}}$ & Baehler et al. 2005 \\
\hline CHA1121 & $\Delta m v a T$ & This study \\
\hline CHA1121-g & CHA1121::attTn7-gfp1; $\mathrm{Km}^{\mathrm{r}}$ & This study \\
\hline CHA1122 & $\Delta r p o N \Delta m v a T$ & This study \\
\hline CHA1124 & CHA1121::attTn7-mvaT $; \mathrm{Gm}^{\mathrm{r}}$ & This study \\
\hline CHA1126 & $\Delta m v a V$ & This study \\
\hline CHA1126-g & CHA1126::att $\mathrm{Tn} 7-g f p 1 ; \mathrm{Km}^{\mathrm{r}}$ & This study \\
\hline CHA1127 & $\Delta m v a T \Delta m v a V$ & This study \\
\hline CHA1127- $g$ & CHA1127::attTn7-gfp $1 ; \mathrm{Km}^{\mathrm{r}}$ & This study \\
\hline CHA1174 & CHA1127::att $\operatorname{Tn} 7-m v a T^{+} ; \mathrm{Gm}^{\mathrm{r}}$ & This study \\
\hline CHA1176 & CHA1126::att $\operatorname{Tn} 7-m v a V^{+} ; \mathrm{Gm}^{\mathrm{r}}$ & This study \\
\hline CHA1177 & CHA1127::att $\operatorname{Tn} 7-m v a V^{+} ; \mathrm{Gm}^{\mathrm{r}}$ & This study \\
\hline CHA1178 & CHA661 $\Delta m v a T ; \mathrm{Km}^{\mathrm{r}}$ & This study \\
\hline CHA1179 & CHA661 $\Delta m v a T \Delta m v a V ; \mathrm{Km}^{\mathrm{r}}$ & This study \\
\hline CHAMS4 & CHA250 mvaT::Tn5; $\mathrm{Km}^{\mathrm{r}}$ & This study \\
\hline \multicolumn{3}{|l|}{ Escherichia coli } \\
\hline FB8 & Wild type & Soutourina et al. 2002 \\
\hline BE1410 & FB8 hns-1001 & Soutourina et al. 2002 \\
\hline DH5 $\alpha$, HB101, W3110 & Laboratory strains & Sambrook and Russell 2001 \\
\hline \multicolumn{3}{|l|}{ Plasmids } \\
\hline pBK-miniTn7-gfp 1 & Delivery plasmid for mini-Tn7-gfp $1 ; \mathrm{Ap}^{\mathrm{r}} \mathrm{Cm}^{\mathrm{r}} \mathrm{Km}^{\mathrm{r}}$ & Koch et al. 2001 \\
\hline pGEM-T Easy & Cloning vector for polymerase chain reaction products & Promega \\
\hline pLG221 & Suicide vector, Coll1 $d r d-1:: \operatorname{Tn} 5, \operatorname{IncI} \alpha ; \mathrm{Km}^{\mathrm{r}}$ & Boulnois et al. 1985 \\
\hline pME497 & Mobilizing plasmid; IncP-1, Tra; RepA(Ts); $\mathrm{Ap}^{\mathrm{r}}$ & Voisard et al. 1994 \\
\hline pME3087 & Suicide vector; ColE1 replicon; RK2-Mob; $\mathrm{Tc}^{\mathrm{r}}$ & Voisard et al. 1994 \\
\hline pME6031 & Cloning vector; $\mathrm{Tc}^{\mathrm{r}}$ & Heeb et al. 2000 \\
\hline pME6182 & Carrier plasmid for $\mathrm{Tn} 7$ containing the mini-Tn7-Gm transposon; $\mathrm{Ap}^{\mathrm{r}} \mathrm{Gm}^{\mathrm{r}}$ & Péchy-Tarr et al. 2005 \\
\hline pME7100 & $p h l A-g f p$ transcriptional fusion; $\mathrm{Tc}^{\mathrm{r}}$ & Baehler et al. 2005 \\
\hline pME7109 & pltA-gfp transcriptional fusion; $\mathrm{Tc}^{\mathrm{r}}$ & Baehler et al. 2005 \\
\hline pME7130 & pUK21 with a 2,251-bp EcoRI-HindIII fragment containing $m v a T$ and its flanking regions & \\
\hline pME7131 & $\begin{array}{l}\text { of } P \text {. fluorescens } \mathrm{CHA} 0 ; \mathrm{Km}^{\mathrm{r}} \\
\text { pUK21 carrying a } 1,656-\mathrm{bp} K p n \mathrm{I}-\mathrm{Xba \textrm {I }} \text { insert with a deletion in } m v a T ; \mathrm{Km}^{\mathrm{r}}\end{array}$ & $\begin{array}{l}\text { This study } \\
\text { This study }\end{array}$ \\
\hline pME7132 & $\begin{array}{l}\text { pUK21 carrying a 1,656-bp KpnI-Xbal insert with a deletion in } m v a I ; \mathrm{Km}^{1} \\
\text { pME3087 carrying the 1,656-bp KpnI-XbaI fragment of pME7131; } \mathrm{Tc}^{\mathrm{r}}\end{array}$ & This study \\
\hline pME7133 & & This study \\
\hline pME7135 & 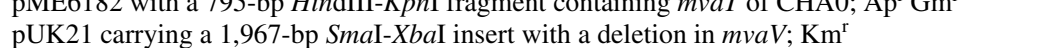 & This study \\
\hline pME7136 & pME3087 carrying the $1,967-\mathrm{bp}$ SmaI-XbaI fragment of pME7135; Tc ${ }^{\mathrm{r}}$ & This study \\
\hline pME7140 & $\begin{array}{l}\text { pUK21 with a 2,319-bp EcoRI-XmaI fragment containing } m v a V \text { and its flanking regions } \\
\text { of } P \text {. fluorescens } \mathrm{CHA} ; \mathrm{Km}^{\mathrm{r}}\end{array}$ & This study \\
\hline pME7141 & pME6031 carrying the 795-bp HindIII-KpnI fragment from pME7133 containing mvaT; $\mathrm{Tc}^{\mathrm{r}}$ & This study \\
\hline pME7142 & pME6182 with a 797-bp HindIII-KpnI fragment containing $m v a V$ of CHA0; $\mathrm{Ap}^{\mathrm{r}} \mathrm{Gm}^{\mathrm{r}}$ & This study \\
\hline pME7143 & pME6031 carrying the 797-bp HindIII-KpnI fragment from pME7142 containing $m v a V$; $\mathrm{Tc}^{\mathrm{r}}$ & This study \\
\hline pUK21 & Cloning vector; lac $Z \alpha ; \mathrm{Km}^{\mathrm{r}}$ & Vieira and Messing 1991 \\
\hline pUX-BF13 & $\begin{array}{l}\text { Helper plasmid for Tn7-based transposon mutagenesis containing the transposition } \\
\text { functions; R6K-replicon; } \mathrm{Ap}^{\mathrm{r}}\end{array}$ & Bao et al. 1991 \\
\hline \multicolumn{3}{|l|}{ Oligonucleotides } \\
\hline ARB1 & GGCCACGCGTCGACTAGTACNNNNNNNNNNGATAT & O'Toole and Kolter 1998 \\
\hline ARB2 & GGCCACGCGTCGACTAGTAC & O'Toole and Kolter 1998 \\
\hline MvaTA & GGAATTCCTGGCAGGAAGCTGTGGTGGA, EcoRI & This study \\
\hline MvaTC & AGTCCCAAGCTTTGACTGGCTGTTCCAGTTGC, HindIII & This study \\
\hline MvaTcompl2 & GGGGTACCTTCTCTGTAGGGCTGCAAA, $K p n \mathrm{I}$ & This study \\
\hline MvaTcompl3 & CCCAAGCTTGGGCAAGAAATCACCAA, HindIII & This study \\
\hline MvaVcompl3 & 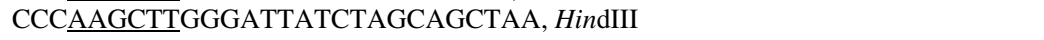 & This study \\
\hline MvaVcompl4 & GGGGTACCCCCTTAGATGCAAGTCGTAATAA, $K p n I$ & This study \\
\hline MvaVPA & CCGGAATTCAGGAGTTCATTCCGTA, EcoRI & This study \\
\hline MvaVPB & TCCCCCGGGAAAGGTATTGAGTTC, XmaI & This study \\
\hline $\mathrm{P} 21$ & TCCCCCGGGAGTTCATTCCGTACTTTCA, SmaI & This study \\
\hline P22 & CCGGAATTCCAATATCTTCACTCCAATAGT, EcoRI & This study \\
\hline $\mathrm{P} 23$ & CCGGAATTCCTGCGCGCTTGAACAAAGCCG, EcoRI & This study \\
\hline P24 & GCTCTAGACCGGGAAAGGTATTGAGTTCG, XbaI & This study \\
\hline P5 & GGGGTACCACCAGGCGCGACACCTCGGCG, $K p n \mathrm{I}$ & This study \\
\hline P6 & CCGGAATTCGATCAGGGACATGAGGACTAC, EcoRI & This study \\
\hline P7 & 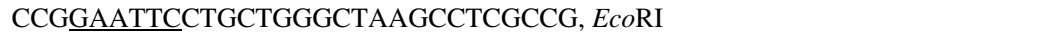 & This study \\
\hline P8 & GCTCTAGACTGGCATCCACGCAATCGCAA, XbaI & This study \\
\hline PTn7glmS & AACATGGCCAAGTCGGTCACC & Péchy-Tarr et al. 2005 \\
\hline PTn7Gm & GGCGGTAGTTGGGTCGATAT & Péchy-Tarr et al. 2005 \\
\hline Tn5Ext & GAACGTTACCATGTTAGGAGGTC & O'Toole and Kolter 1998 \\
\hline Tn5Int & CGGGAAAGGTTCCGTTCAGGACGC & O’Toole and Kolter 1998 \\
\hline
\end{tabular}

${ }^{\mathrm{y}} \mathrm{Ap}^{\mathrm{r}}=$ ampicillin resistance; $\mathrm{Cm}^{\mathrm{r}}=$ chloramphenicol resistance; $\mathrm{Gm}^{\mathrm{r}}=$ gentamicin resistance; $\mathrm{Km}^{\mathrm{r}}=$ kanamycin resistance; $\mathrm{Tc}^{\mathrm{r}}=$ tetracycline resistance.

${ }^{\mathrm{z}}$ Specified restriction sites are underlined. 
acids with TurB (PP3765), a homolog of the repressor TurA (Rescalli et al. 2004). MvaV is also similar to an H-NS-like protein of Pseudomonas sp. strain Y1000 (Tendeng et al. 2003; $58 \%$ identity) and to MvaU, an MvaT homolog of P. aeruginosa PAO1 (Vallet et al. 2004; 55\% identity). The deduced product of the only partially sequenced ORFC upstream of mvaV shows similarities with the C-termini of conserved hypothetical proteins of $P$. aeruginosa PA01 (PA3825, 69\% identity) and $P$. putida KT2440 (PP3435, 74\% identity). The divergently oriented downstream gene (ORFD) encodes a protein that displays some similarity with hypothetical proteins of Pseudomonas syringae pv. tomato DC3000 (PSPTO3105, GenBank accession number NP_792897; 57\% identity) and P. aeruginosa PAO1 (PA2434, 47\% identity). The adjacent ORFE was sequenced only in its $5^{\prime}$ region. Its deduced amino acid sequence is very similar to the N-terminal sequence of a lactoylglutathione lyase of $P$. putida (PP3766) and P. syringae (PSPTO3106). A similar gene arrangement occurs in P. fluorescens Pf0-1 (Fig. 1B, GenBank accession number AAAT03000000, locus tags Pflu02001255 through Pflu02001257) but appears not to be conserved in other Pseudomonas species (data not shown).

In silico analysis establishes MvaT and MvaV of $P$. fluorescens CHA0 as novel members of the emerging family of MvaT-like proteins in Pseudomonas species (Diggle et al. 2002; Tendeng et al. 2003). The amino acid sequences of $\mathrm{MvaT}$ and MvaV of strain CHA0 were aligned with sequences of MvaT-like proteins compiled from available genomic data of members of the Pseudomonadaceae family (Fig. 2A) and a phylogenetic tree was generated (Fig. 2B). The MvaT-like proteins are of similar size (117 to 126 amino acid residues) and share at least $40 \%$ identity among each other (Fig. 2A). Significant homologies can be detected in particular in the C-terminal domains of these proteins (Fig. 2A). Three main groups of MvaT-like proteins can be defined, with MvaT and MvaV of strain CHA0 clustering in groups I and II, respectively (Fig. 2B). Interestingly, three putative members of the MvaT family can be detected in P. fluorescens strains Pf0-1, SBW25, and Pf-5, each protein clustering in a separate group (Fig. 2B). For instance, a putative MvaT homolog termed PFL_4981 clustering in group III can be identified in P. fluorescens Pf-5 (Fig. 2B). PFL_4981 displays $49 \%$ and $55 \%$ amino acid identity with MvaT and MvaV, respectively, of strain CHA0. However, despite several attempts, we were not able to detect a chromosomal locus coding for the corresponding protein in CHA0 (data not shown), suggesting that this strain, like $P$. aeruginosa (Fig. 2B), possesses only two MvaT-like proteins.

\section{MvaT and MvaV}

are functionally and structurally related to $\mathrm{H}-\mathrm{NS}$ of $\boldsymbol{E}$. coli.

There is some evidence that members of the MvaT protein family are functionally and structurally related to the nucleoidassociated protein H-NS of enterobacteria, although sharing no significant homology (Dame et al. 2005; Rescalli et al. 2004;
Tendeng and Bertin 2003; Tendeng et al. 2003). To determine whether this observation holds true for MvaT and $\mathrm{MvaV}$ of $P$. fluorescens $\mathrm{CHA} 0$, we have mobilized the low-copy-number vectors pME7141 and pME7143, containing mvaT and mvaV (Table 1), respectively, into the E. coli hns mutant BE1410 (provided by P. N. Bertin). The hns mutant displays phenotypes that are typically associated with H-NS deficiency, i.e., a mucoid phenotype, lack of flagella, and loss of motility (Bertin et al. 1994; Soutourina et al. 2002; Tendeng et al. 2003). Remarkably, flagellation and motility in the E. coli hns mutant could be fully restored by expression of the P. fluorescens mvaV gene and at least partially by mvaT (Table 2). Heterologous expression of mvaT and mvaV also reversed the mucoid phenotype of the hns mutant BE1410 to the nonmucoid phenotype displayed by the parental strain (Table 2). Mobilization of the empty vector control (pME6031) into strain BE1410 had no such effects (Table 2). Although, MvaT and MvaV of $P$. fluorescens show no significant homology with H-NS proteins at the level of their amino acid sequence (e.g., $<18 \%$ identity with $\mathrm{H}-\mathrm{NS}$ of $E$. coli), they are structurally related to $\mathrm{H}-\mathrm{NS}$, as evidenced by a secondary structure consensus prediction method (Combet et al. 2000) available at the Network Protein Sequence Analysis website. Using this method, the N-terminal domains of MvaT and MvaV are predicted to be mainly $\alpha$ helical while their highly conserved C-terminal domains (Fig. 2A) are mixed $\alpha$ and $\beta$ structures (data not shown). The $\mathrm{N}$ - and C-terminal domains are connected by a central linker region that appears to be highly variable in the MvaT protein family (Fig. 2A). These structural characteristics are in accordance with those reported recently for H-NS of E. coli and an MvaTlike protein of Pseudomonas sp. strain Y1000 (Dame et al. 2005; Tendeng et al. 2003). In E. coli, the N-terminal domain of H-NS has oligomerization activity, whereas the C-terminal domain has nucleic acid-binding activity (Dorman 2004; Rimsky 2004; Tendeng and Bertin 2003).

\section{Growth characteristics \\ of $\mathrm{mvaT}$ and $\mathrm{mvaV}$ mutants of $P$. fluorescens.}

To study the role of MvaT and MvaV, we created in framedeletion mutations in the corresponding genes in P. fluorescens CHAO as described below. The resulting mvaT mutant CHA1121 and the mvaV mutant CHA1126 (Fig. 1) were complemented with monocopy wild-type mvaT and mvaV, respectively, introduced into the chromosomal $\mathrm{Tn} 7$ attachment site, giving strains CHA1124 and CHA1176 (Table 1). In addition, an mvaT mvaV double mutant (CHA1127) was constructed and complemented with a single copy of wild-type mvaT or mvaV, resulting in strains CHA1174 and CHA1177 (Table 1), respectively. The $m v a T$ and $m v a V$ mutants were indistinguishable from the wild type and the complemented mutants with respect to their growth characteristics in nutrient-rich media such as King's medium B (KMB) and Luria-Bertani (LB) broth and in minimal glucose-ammonium (OSG) and glycerol-

Table 2. Complementation of H-NS deficiency in Escherichia coli by heterologous expression of Pseudomonas fluorescens mvaT and mvaV genes

\begin{tabular}{|c|c|c|c|c|}
\hline Strain & Relevant genotype & Mucoidy $^{x}$ & Flagella $^{y}$ & Motility $^{\mathrm{z}}$ \\
\hline FB8 & Wild type & - & + & $100 \pm 3$ \\
\hline BE1410 & hns-1001 & + & - & $6 \pm 1$ \\
\hline BE1410/pME6031 & hns-1001/- & + & - & $5 \pm 1$ \\
\hline BE1410/pME7141 & $h n s-1001 / m v a T^{+}$ & - & $+1-$ & $63 \pm 5$ \\
\hline BE1410/pME7143 & hns-1001/mvaV & - & + & $116 \pm 3$ \\
\hline
\end{tabular}

${ }^{\mathrm{x}}+=$ mucoid phenotype (Schnider-Keel et al. 2001) observed on nutrient agar after incubation for $16 \mathrm{~h}$ at $37^{\circ} \mathrm{C} ;-=$ nonmucoid phenotype.

${ }^{\mathrm{y}}+=$ cells were flagellated; $-=$ cells were nonflagellated; $+/-=$ only about half of the cells were flagellated. Bacterial cells were taken from the edge of swarm colonies and were observed by transmission electron microscopy (Péchy-Tarr et al. 2005).

${ }^{\mathrm{z}}$ Motility was scored as the diameter of bacterial displacement on swarm plates after incubation for $48 \mathrm{~h}$ at $30^{\circ} \mathrm{C}$. Data are expressed as a percentage of the diameters obtained for the E. coli wild-type strain FB8 (i.e., $72.6 \pm 2.3 \mathrm{~mm}$ ), which were arbitrarily set to $100 \%$. Data represent the means \pm standard deviation from five replicate plates per treatment. The experiment was repeated twice with similar results. 


\section{A}

SBW25-2158

PP1366

PSPTO4315

PSyro3004

Avin02001282

Presin

CHAO-MvaV

PFL 3391

SBW $25-1923$

PSPT03103

Psyr03003751

PP3765

PA2667

PP2 947

PP3693

PP0017

PSPTO4755

Psyr03003809

Pflu02001

SBW25-2822
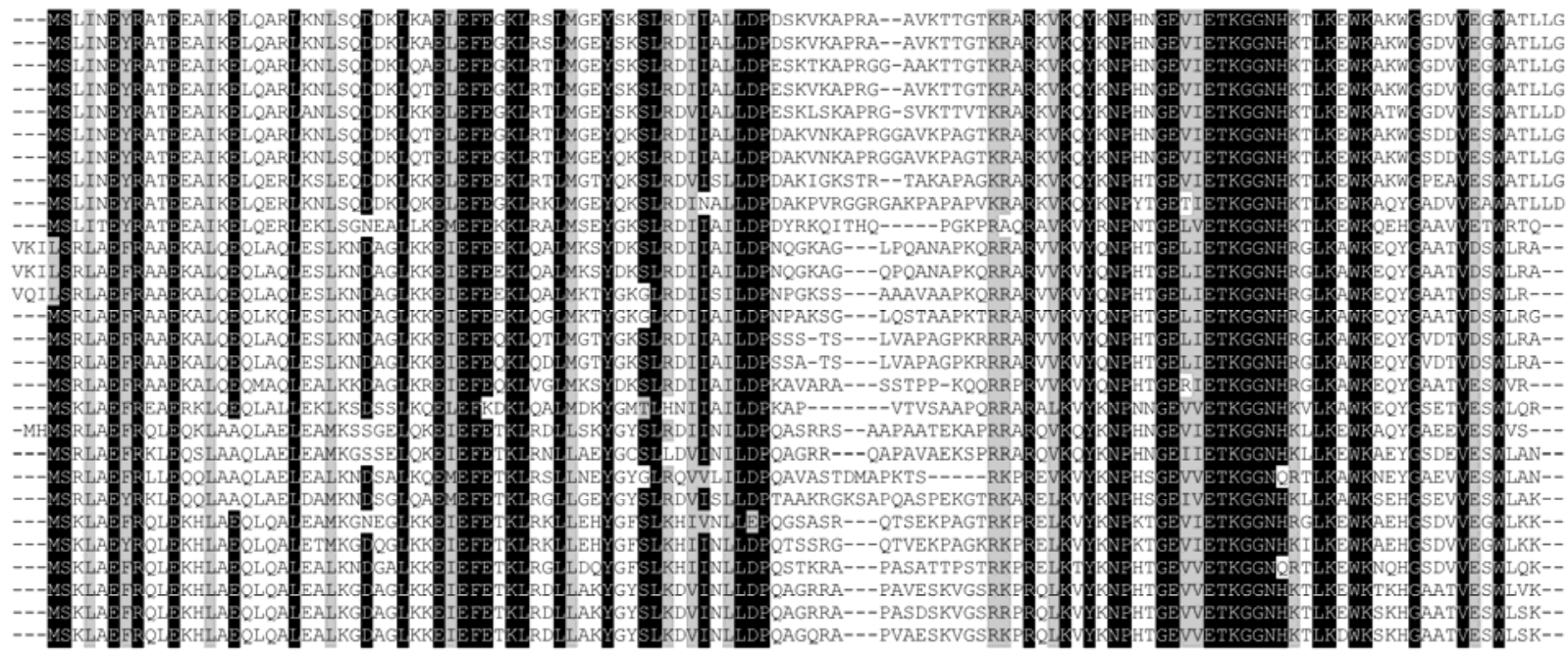

B 
ammonium (OSGly) media (data not shown). The mvaT mvaV double mutant CHA1127 displayed wild-type growth rates in LB broth but had a longer doubling time in KMB broth (approximately $47 \mathrm{~min}$ for the mutant versus 35 for the wild type), in OSG (102 versus 60), and in OSGly (97 versus 71). In all media tested, strain CHA1127 attained lower final cell densities in the stationary phase (data not shown). Interestingly, the mvaT mvaV double mutant developed a pronounced mucoid phenotype when grown on nutrient agar (NA) plates. All these growth characteristics could be reversed to those typical of the wild type when strain CHA1127 was complemented with intact monocopy mvaT or mvaV (data not shown).

\section{MvaT and MvaV control the production of antifungal compounds in $\boldsymbol{P}$. fluorescens.}

To determine the effect of MvaT and MvaV on DAPG and PLT biosynthetic gene expression, we monitored the expression of $g f p$ reporter fusions to phlA and pltA (Baehler et al. 2005), respectively, in $P$. fluorescens CHA0 and its mvaT and mvaV mutants growing in OSGly medium. The loss of MvaT or MvaV function in strains CHA1121 and CHA1126, respectively, enhanced the expression of the $p h l A-g f p$ fusion carried by pME7100 (Baehler et al. 2005) by approximately 10 to $30 \%$ throughout the exponential and stationary growth phases as compared with the wild-type CHA0 (Fig. 3A). The expression of the PLT biosynthetic gene pltA was markedly more affected by a lack of MvaT or MvaV. Indeed, the expression of a pltA-gfp fusion carried by pME7109 (Baehler et al. 2005) was increased by up to $170 \%$ in the mvaT mutant CHA1121 and by up to $40 \%$ in the mvaV mutant CHA1126, as compared with the parental strain (Fig. 3B). Remarkably, derepression of PLT gene expression was even more pronounced in an mvaT mvaV double mutant as evidenced by a strongly advanced and severalfold enhanced expression of the pltA-gfp reporter fusion in strain CHA1127 (Fig. 3B). Interestingly, phlA-gfp expression was strongly repressed in the double mutant (Fig. 3A). Similar results were obtained when the effects of MvaT and MvaV on antifungal gene expression were tested in $\mathrm{KMB}$ and $\mathrm{KMB}$ malt broth (data not shown).

Kinetics of DAPG and PLT production were monitored for bacteria grown in KMB malt and KMB broth, respectively, and largely reflected the results obtained with the $p h l A-g f p$ and pltA-gfp reporter fusions. KMB broth supports production of PLT (Maurhofer et al. 1994) and DAPG production is favored by addition of malt extract to this medium (Baehler et al. 2005). DAPG production in the mvaT and mvaV mutants remained about at wild-type levels (Fig. 4A). PLT levels were up to threefold higher in the mvaT mutant CHA1121 and were increased by about $30 \%$ in the mvaV mutant CHA1126, as compared with the wild-type CHA0 (Fig. 4B). Maximum PLT levels $(579 \pm 80 \mu \mathrm{M}$ after $75 \mathrm{~h})$ measured in KMB cultures of the mvaT mvaV double mutant CHA1127 were more than 20-fold higher than those attained by the wild type (Fig. 4B). By con- trast, DAPG production was completely abolished in strain CHA1127 growing in KMB malt broth. The double mutant CHA1127 accumulated up to $391 \pm 36 \mu \mathrm{M}$ PLT in KMB malt broth, whereas the wild-type CHA0 and its mvaT and mvaV

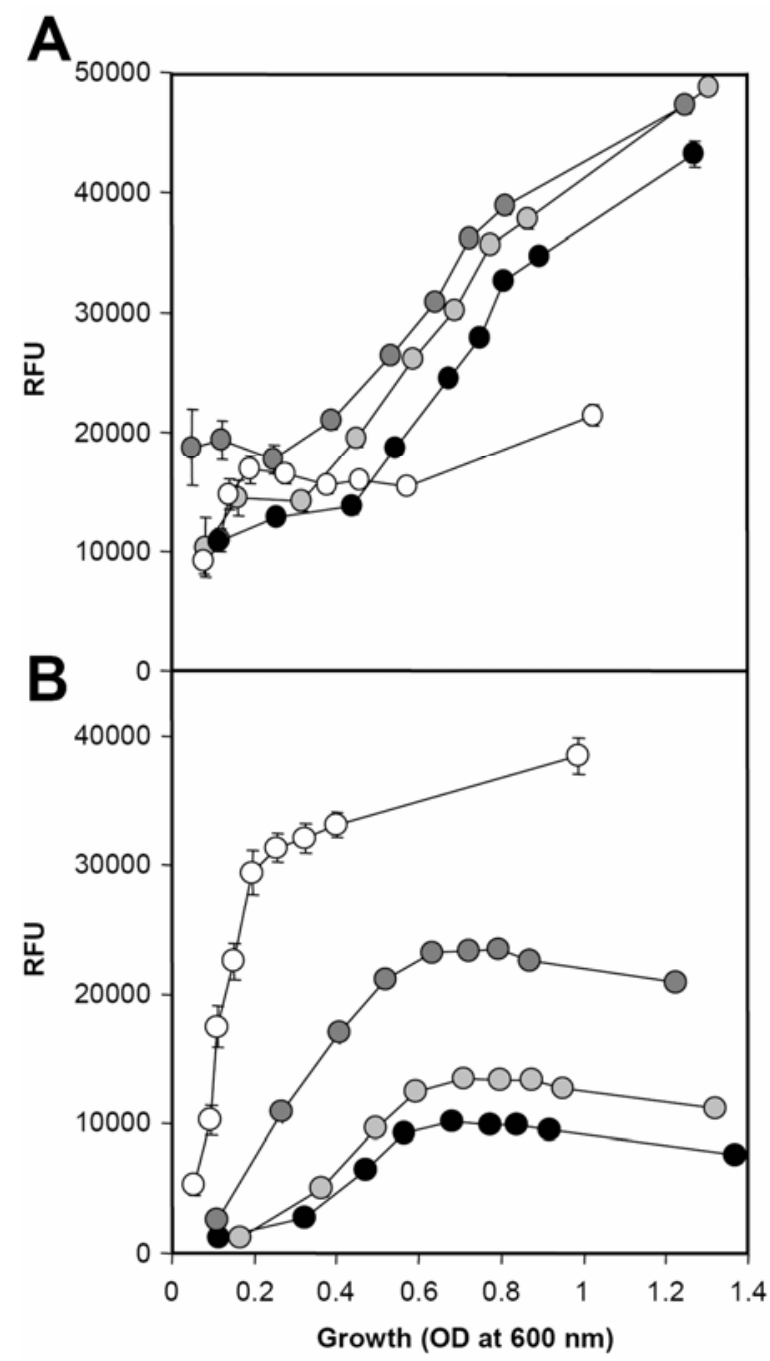

Fig. 3. MvaT and MvaV control of the expression of 2,4-diacetylphloroglucinol and pyoluteorin biosynthetic genes in Pseudomonas fluorescens CHA0. Expression of the plasmid-borne reporter fusions A, phlA-gfp (pME7100) and B, pltA-gfp (pME7109) in growing cultures of wild-type CHA0 (indicated by black circles [0]), the mvaT in frame-deletion mutant CHA1121 (dark gray circles [O]), the mvaV in frame-deletion mutant CHA1126 (light gray circles [O]), and the mvaT mvaV double mutant CHA1127 (open circles [O]). Strains were grown in glycerol-ammonium medium at $30^{\circ} \mathrm{C}$. Means \pm standard deviations from six replicate cultures are shown. The experiment was repeated twice with similar results. Some of the error bars were too small to be shown.

Fig. 2. A, Alignment of amino acid sequences of MvaT and MvaV of Pseudomonas fluorescens CHA0 with sequences of MvaT-like proteins compiled from available complete and unfinished genomes of members of the Pseudomonadaceae family. Identical residues (black boxes) and similar residues (gray boxes) are indicated. B, Deduced phylogenetic tree generated by the neighbor-joining method with the Nei-Kumar gamma parameter correction of evolutionary distances (Kumar et al. 2001). Nodal supports in the phylogenetic tree were assessed by bootstrap resampling (1,000 replicates). The scale bar represents the number of substitutions per site. PFL = P. fluorescens Pf-5 (GenBank accession number CP000076; Paulsen et al. 2005); Pflu = P. fluorescens Pf0-1 (accession number AAAT03000000; Microbial Genomics website); SBW25 = P. fluorescens SBW25 (Sanger Institute website); PP = P. putida KT2440 (accession number AE015451; Nelson et al. 2002); PSPT $=$ P. syringae pv. tomato DC3000 (accession number AE016853; Buell et al. 2003); Psyr = P. syringae pv. syringae B728a (accession number AABP00000000; Microbial Genomics website); PA = P. aeruginosa PAO1 (accession number AE004091; Stover et al. 2000); Presin $=$ P. resinovorans CA10 (accession number BAC41590); PY1000 = Pseudomonas sp. strain Y1000 (accession number CAD98777; Tendeng et al. 2003); Avin = Azotobacter vinelandii AvOP (accession number AAAU00000000; Microbial Genomics website); Pmev = P mevalonii (accession number AAC46083; Rosenthal and Rodwell 1998); Paer = P. aeruginosa UCBPP-PA14 (accession number AABQ00000000; ParaBioSys website). The unfinished genomes of $P$. fluorescens strains Pf-5, Pf0-1, and SBW25, and of $P$. syringae pv. syringae B728a were partly analyzed using programs available at the PseudoDB website. The amino acid alignment was achieved using Clustal W (Thompson et al. 1994). 
mutants were unable to produce the antibiotic in this medium. The high concentrations of PLT present in the culture may have accounted for this effect, since PLT is known to be a potent inhibitor of DAPG gene expression in $P$. fluorescens (Baehler et al. 2005; Schnider-Keel et al. 2000). To test this hypothesis, we constructed the pltC::Tn5 $\Delta$ mvaT $\Delta m v a V$ triple mutant CHA1179 (Table 1), which is unable to produce PLT. Indeed, DAPG production was fully restored in this mutant and reached levels that were even slightly higher than those in the wild-type CHA0 (Fig. 5). The strong decrease of DAPG and PLT levels at the end of the experiments (Figs. 4 and 5) may be due to the degradation of the two metabolites by the producer strains (Baehler et al. 2005; Schnider-Keel et al. 2000; M. Bottiglieri and C. Keel, unpublished findings). A sharp decrease of PLT concentrations in cultures of the mvaT and mvaT mvaV mutants could only be observed after prolonged incubation for up to $200 \mathrm{~h}$ (data not shown) and then was accompanied by the appearance of an unidentified dark red pigment that has been observed previously in certain DAPG-producing pseudomonads (Keel et al. 1996).

DAPG and PLT production and expression of the corresponding biosynthetic genes in CHA1121 ( $\Delta m v a T)$ and CHA1126 ( $\Delta m v a V$ ) could be restored to wild-type levels by complementation with single-copy intact mvaT and mvaV, respectively (data not shown). In the same vein, the PLT-overproducing and DAPG-nonproducing phenotype of the mvaT mvaV double mutant CHA1127 could be reversed by complementation with monocopy parental mvaT to an MvaV-negative phenotype, with kinetics of DAPG and PLT production resembling those of the wild-type CHA0 (data not shown). Collectively, these results indicate that MvaT and MvaV may act in concert to control the balance of antibiotic production in $P$. fluorescens.

\section{Effect of MvaT and MvaV}

\section{on other exoproducts in $P$. fluorescens.}

To determine if the effects of the mvaT and mvaV mutations were not restricted to the antifungal compounds DAPG and
PLT, we also examined production of other exoproducts, in particular, HCN, exoenzymes, and siderophores that may contribute to some extent to the biocontrol ability of $P$. fluorescens (Haas and Défago 2005; Haas and Keel 2003; Voisard et al. 1989). Effects on HCN production were monitored in oxygenlimited KMB cultures. Lack of either MvaT or MvaV had no effect on $\mathrm{HCN}$ production, whereas loss of both regulators in

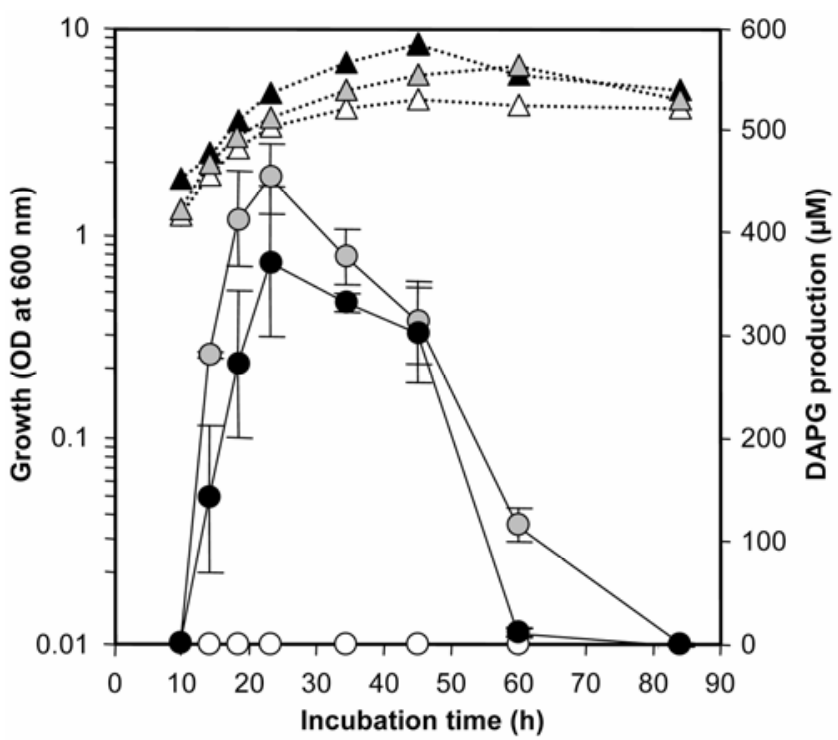

Fig. 5. Influence of MvaT and $\mathrm{MvaV}$ on the biosynthesis of 2,4-diacetylphloroglucinol in the absence of pyoluteorin (PLT) production in Pseudomonas fluorescens. The wild-type CHA0 (black circles [-]), the $\triangle m v a T$ $\Delta m v a V$ double mutant CHA1127 (open circles [O]), and the PLT-negative pltC::Tn5 $\Delta m v a T \Delta m v a V$ triple mutant CHA1179 (light gray circles [O]) were grown in King's medium B malt broth at $27^{\circ} \mathrm{C}$. The black, open, and light gray triangles $(\boldsymbol{\Delta}, \triangle$, and $\Delta$ ) indicate growth (optical densities at $600 \mathrm{~nm}$ ) of strain CHA0, CHA1127, and CHA1179, respectively. Means \pm standard deviation from three replicate cultures are shown. The experiment was repeated twice, with similar results.
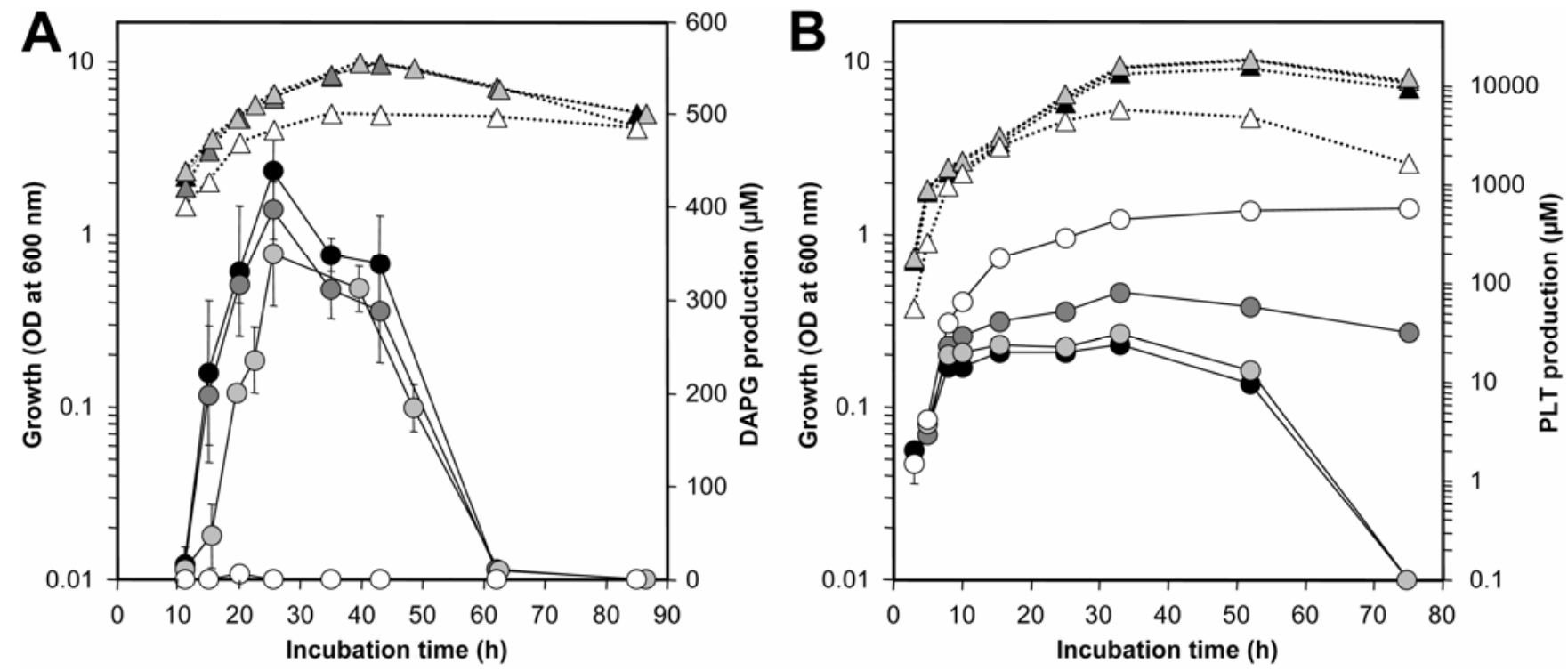

Fig. 4. MvaT and MvaV control of A, 2,4-diacetylphloroglucinol (DAPG) and B, pyoluteorin (PLT) production in Pseudomonas fluorescens CHA0. The wild-type CHA0 (indicated by black circles [-]), the $\Delta m v a T$ mutant CHA1121 (dark gray circles [O]), the $\Delta m v a V$ mutant $\mathrm{CHA} 1126$ (light gray circles [○]), and the $\triangle m v a T \Delta m v a V$ double mutant CHA1127 (open circles [O]) were cultured in King's medium B (KMB) malt broth at $27^{\circ} \mathrm{C}$ (for DAPG production) and in $\mathrm{KMB}$ broth at $30^{\circ} \mathrm{C}$ (for PLT production). The black, dark gray, light gray, and open triangles $[\mathbf{\Delta}, \Delta, \Delta$, and $\triangle$ ] indicate growth (optical densities at $600 \mathrm{~nm}$ ) of strain CHA0, CHA1121, CHA1126, and CHA1127, respectively. Note that PLT concentrations are represented on a logarithmic scale due to the massive production of this compound by CHA1127. Means \pm standard deviation from three replicate cultures are shown. The experiment was repeated twice, with similar results. Some of the error bars were too small to be included. 
strain CHA1127 led to a significant increase of HCN levels by about $20 \%$ as compared with the wild-type CHA0 (Table 3 ). HCN production was reversed to wild-type levels by complementation of CHA1127 with intact mvaT (Table 3).

Activity of extracellular protease was determined colorimetrically in cell-free supernatants from $\mathrm{KMB}$ overnight cultures. Deletion of mvaT in strain CHA1121 resulted in an almost $50 \%$ enhanced exoprotease activity compared with the wild type, whereas no such effect could be observed for the mvaV mutant CHA1126 (Table 3). Loss of both MvaT and MvaV function in strain CHA1127 led to a further increase of exoprotease activity (Table 3 ). Enhanced exoprotease activity in strains CHA1121 and CHA1127 could be reversed to near wild-type levels by complementation with intact mvaT (Table 3 ). Analogous results were obtained when measuring exoprotease activity as the zone of clearance formed around droplets of bacterial overnight cultures spotted on skim milk agar plates (data not shown).

In contrast to the above observations, a lack of MvaT and $\mathrm{MvaV}$ resulted in reduced phospholipase $\mathrm{C}$ and siderophore activity. Phospholipase activity determined with a blood agar assay was lowered by about $40 \%$ in the mvaT mvaV double mutant CHA1127 as compared with the wild type and the mutant complemented with parental mvaT (Table 3). Similarly, siderophore activity analyzed with the chrome azurol assay (Schwyn and Neilands 1987) was strongly reduced (by about $60 \%$ ) in the double mutant CHA1127 (Table 3). By contrast, the single mvaT or mvaV deletions in strains CHA1121 and CHA1126, respectively, had no such effects on phospholipase or siderophore activity (Table 3). Taken together, these findings point to a role for MvaT and $\mathrm{MvaV}$ as novel global regulators of exoproduct formation in P. fluorescens.
MvaT and MvaV influence motility, biosurfactant activity, and physicochemical cell surface properties

of $P$. fluorescens.

Previously, we have described three modes of surface translocation for $P$. fluorescens, i.e., swimming, swarming, and twitching motility (Péchy-Tarr et al. 2005). In the mvaT mutant CHA1121, swimming and swarming motilities were significantly enhanced by about 40 and $30 \%$, respectively, compared with the wild-type CHA0 and the complemented mutant CHA1124 (Table 4). The mvaV mutant CHA1126 displayed wild-type swarming behavior and had a slightly, yet not significantly, reduced swimming capacity (Table 4). Interestingly, swimming and swarming activities were strongly reduced in CHA1127, which lacks both MvaT and MvaV (Table 4). Complementation of the double mutation with a single copy of wild-type mvaT in CHA1174 or mvaV in CHA1177 reversed swarming and swimming motilities to levels resembling those of the mvaV mutant CHA1126 and the mvaT mutant CHA1121, respectively (Table 4). Twitching motility remained at wild-type levels in the mvaV mutant but was reduced by about $25 \%$ in the mvaT mutant and the mvaT mvaV double mutant (Table 4). Examination of cells taken from the edge of swarm colonies by transmission electron microscopy revealed that all three mutants possessed the same number of polar flagella (i.e., two or three, sometimes more) as the wild type (data not shown).

Pseudomonads are known to release biosurfactants that can influence their surface motility and their interaction with hydrophobic surfaces (Andersen et al. 2003; Déziel et al. 2003; Kuiper et al. 2004). In this work, analysis of biosurfactant activity was followed by analyzing the surface tension $(\sigma)$ of supernatants of bacterial cultures grown in KMB broth. Surface

Table 3. Effect of mvaT and mvaV mutations on hydrogen cyanide (HCN), exoenzyme, and siderophore production in Pseudomonas fluorescens $\mathrm{CHA} 0^{\mathrm{v}}$

\begin{tabular}{|c|c|c|c|c|c|}
\hline Strain & Relevant genotype & $\begin{array}{l}\text { HCN production } \\
\left(\mathrm{nmol}^{\prime} \mathbf{1 0}^{\mathbf{9}} \text { cells }\right)^{\mathrm{w}}\end{array}$ & $\begin{array}{l}\text { Exoprotease activity } \\
(\text { (P.U.) })^{\mathrm{x}}\end{array}$ & $\begin{array}{l}\text { Phospholipase } \\
\text { activity }(\% \text { wt })^{y}\end{array}$ & $\begin{array}{c}\text { Siderophore } \\
\text { production }(\% \mathrm{wt})^{\mathrm{z}}\end{array}$ \\
\hline CHA0 & Wild type & $85.2 \pm 0.9$ & $94.7 \pm 5.8$ & $100 \pm 16$ & $100 \pm 4$ \\
\hline CHA1121 & $\Delta m v a T$ & $88.8 \pm 6.3$ & $138.9 \pm 6.1$ & $96 \pm 14$ & $96 \pm 2$ \\
\hline CHA1124 & $\Delta m v a T$ att $\operatorname{Tn} 7-m v a T^{+}$ & $80.3 \pm 13.0$ & $72.9 \pm 1.4$ & $100 \pm 16$ & $100 \pm 4$ \\
\hline CHA1126 & $\Delta m v a V$ & $86.9 \pm 13.1$ & $98.4 \pm 3.4$ & $96 \pm 14$ & $98 \pm 4$ \\
\hline CHA1127 & $\Delta m v a T \Delta m v a V$ & $104.0 \pm 10.4$ & $180.4 \pm 2.9$ & $58 \pm 17$ & $39 \pm 4$ \\
\hline CHA1174 & $\Delta m v a T \Delta m v a V$ att $\operatorname{Tn} 7-m v a T^{+}$ & $77.7 \pm 4.9$ & $79.7 \pm 2.4$ & $96 \pm 14$ & $98 \pm 4$ \\
\hline
\end{tabular}

${ }^{v}$ Data represent the means \pm standard deviation from four to six replicate cultures per treatment. All experiments were repeated at least once with similar results.

${ }^{\mathrm{w}} \mathrm{HCN}$ production was determined for cultures grown for $24 \mathrm{~h}$ in King's medium B (KMB) broth under oxygen-limited conditions. All cultures reached an optical density at $600 \mathrm{~nm}\left(\mathrm{OD}_{600} \mathrm{~nm}\right)$ of 1.0 to 1.1 at the time of sampling.

${ }^{\mathrm{x}}$ Exoprotease production was measured on cell-free supernatant from overnight cultures grown in $20 \mathrm{ml}$ of KMB broth contained in $100-\mathrm{ml}$ flasks. All cultures reached an $\mathrm{OD}_{600}=5.5$ to 7.0 at the time of sampling. Data are expressed as P.U.

${ }^{\mathrm{y}}$ Phospholipase activity was determined by measuring the clear halos forming around bacterial growth $30 \mathrm{~h}$ after spotting $10 \mu \mathrm{l}$ of overnight cultures (adjusted to $\mathrm{OD}_{600}=1.0$ ) on blood agar plates. Data are expressed as a percentage of the halo diameters obtained for the wild type, which were arbitrarily set to $100 \%$.

${ }^{\mathrm{z}}$ Siderophore production was detected by the appearance of orange halos around bacterial growth $24 \mathrm{~h}$ after spotting $10 \mu \mathrm{l}$ of overnight cultures (adjusted to $\left.\mathrm{OD}_{600}=1.0\right)$ on chrome azurol S plates. Data are expressed as a percentage of the halo diameters obtained for the wild type, which were arbitrarily set to $100 \%$.

Table 4. Contribution of MvaT and MvaV to surface motility of Pseudomonas fluorescens ${ }^{\mathrm{z}}$

\begin{tabular}{|c|c|c|c|c|}
\hline Strain & Relevant genotype & Swim area & Swarm area & Twitch area \\
\hline $\mathrm{CHAO}$ & Wild type & $100 \pm 22$ & $100 \pm 10$ & $100 \pm 9$ \\
\hline CHA1121 & $\Delta m v a T$ & $140 \pm 16$ & $133 \pm 12$ & $75 \pm 9$ \\
\hline CHA 1124 & $\Delta m v a T$ att $\operatorname{Tn} 7-m v a T^{+}$ & $95 \pm 12$ & $112 \pm 11$ & $85 \pm 6$ \\
\hline CHA1126 & $\Delta m v a V$ & $84 \pm 19$ & $103 \pm 15$ & $99 \pm 14$ \\
\hline CHA 1176 & $\Delta m v a V$ att $\operatorname{Tn} 7-m v a V^{+}$ & $108 \pm 14$ & $111 \pm 5$ & n.d. \\
\hline CHA 1127 & $\Delta m v a T \Delta m v a V$ & $52 \pm 8$ & $41 \pm 9$ & $76 \pm 3$ \\
\hline CHA1174 & $\Delta m v a T \Delta m v a V$ att $\operatorname{Tn} 7-m v a T^{+}$ & $90 \pm 11$ & $95 \pm 5$ & $89 \pm 6$ \\
\hline CHA1177 & $\Delta m v a T \Delta m v a V$ att $\operatorname{Tn} 7-m v a V^{+}$ & $119 \pm 14$ & $122 \pm 7$ & n.d. \\
\hline
\end{tabular}

${ }^{\mathrm{z}}$ Diameter of bacterial displacement on swim plates, swarm plates, and twitch plates after incubation for $24 \mathrm{~h}$ (swim and swarm plates) and 5 days (twitch plates) at room temperature, assessed as described previously (Péchy-Tarr et al. 2005). Data are expressed as a percentage of the diameters obtained for wild-type strain CHA0, which were arbitrarily set to $100 \%$. Data represent the means \pm standard deviation from five replicate plates per treatment. The experiment was repeated twice with similar results. n.d. $=$ not determined. 
tensions depended on the growth phase of the individual strains. No microbially induced reduction of $\sigma$ was observed in any of the strains in the early exponential growth phase (data not shown). In the late exponential phase, however, $\sigma$ of supernatants of the mvaT mvaV double mutant CHA1127 dropped by more than $20 \mathrm{mN} / \mathrm{m}$ relative to the wild type, its $m v a T$ and mvaV mutants, and sterile KMB broth used as a control (Table 5). Surface tension results were corroborated by emulsifying activity testing of late exponential culture supernatants according to the toluene-mixing method described by Kuiper and associates (2004). Compared with the wild-type CHA0 and the mvaT and mvaV mutants, the double mutant CHA1127 had an enhanced capacity for forming water-toluene emulsions (data not shown). The reduction of $\sigma$ and emulsifying activity in the double mutant suggests a combined negative influence of MvaT and MvaA on the production of surface-active compounds in strain CHA0.

In order to evaluate the influence of mvaT and mvaV on physicochemical cell surface properties, the water contact angles $\left(\theta_{\mathrm{w}}\right)$ and zeta potential $(\zeta)$ were measured to describe surface charge and surface hydrophobicity of $P$. fluorescens CHA 0 and its derivatives. $\theta_{\mathrm{w}}$ and $\zeta$ are known to influence adhesion and, concomitantly, the mobility of bacteria on surfaces (Redman et al. 2004). According to the so-called extended DLVO theory of colloidal stability (van Oss 1994) in which electrostatic repulsion, van der Waals attraction, and acid-base (hydrophobic) interactions are considered, the adhesion capacity is inversely correlated with a more negative surface charge and favored by the hydrophobicity of the bacterial cells. $\theta_{\mathrm{w}}$ values of strain $\mathrm{CHAO}$ and its mutant derivatives were in the range of 32 to 44 degrees (Table 5) and thus can be considered as intermediate hydrophilic (Rijnaarts et al. 1993). The lowest $\theta_{\mathrm{w}}$ values were observed for the mvaT mvaV double mutant (Table 5). All bacterial strains tested were negatively charged and showed minimal differences in their $\zeta$ values only (Table 5). Earlier findings have demonstrated that the whole-cell isoelectric point (IEP, i.e. the $\mathrm{pH}$ at which $\zeta$ becomes zero) is a suitable indicator in predicting the affinity of bacteria for surfaces with different hydrophobicities (Rijnaarts et al. 1995). Literature data demonstrate that an IEP $\leq 2.8$ indicates the presence of significant amounts of cell surface polysaccharides inhibiting adhesion onto both hydrophobic and hydrophilic surfaces (Rijnaarts et al. 1995). Continuously decreasing $\zeta$ values between $\mathrm{pH} 2$ and $\mathrm{pH} 5.5$ and no changes of the IEP were found for all bacterial strains tested (Table 5). The observed IEP of 2.9 to 3 (Table 5) is lower than published IEP values of other Pseudomonas strains (Rijnaarts et al. 1995), possibly indicating the presence of significant amounts of polysaccharides at the cell surface of strain $\mathrm{CHA} 0$ and its derivatives.

\section{MvaT and MvaV are required for biocontrol capacity of $\boldsymbol{P}$. fluorescens.}

To determine the relative contributions of MvaT and MvaV to biocontrol capacity of $P$. fluorescens CHA0, plant assays were set up in natural soil microcosms, involving cucumber as the host plant and Pythium ultimum as a pathogen causing a root rot and damping-off disease. Addition of strain CHA0 to pathogen-infested soil enhanced plant survival by about $30 \%$ and plant fresh weights were increased nearly threefold compared with a control without biocontrol bacteria added (Table 6). Both the mvaT mutant CHA1121 and the mvaV mutant CHA1126 were significantly impaired in their capacity to pro-

Table 5. Influence of mvaT and mvaV mutations on physicochemical cell surface properties and surface tension of culture supernatants of Pseudomonas fluorescens $\mathrm{CHA} 0^{\mathrm{w}}$

\begin{tabular}{|c|c|c|c|c|c|c|}
\hline Strain & Relevant genotype & $\begin{array}{c}\text { Zeta potential } \\
(\zeta)(\mathbf{m V})\end{array}$ & $\begin{array}{c}\text { Slope of } \zeta \text { vs. pH } \\
{[\mathrm{mV} \text { (pH-unit) }]}\end{array}$ & $\begin{array}{c}\text { Isoelectric point } \\
(\text { IEP })^{\mathbf{x}}\end{array}$ & $\begin{array}{c}\text { Water contact angle } \\
\left(\theta_{w}\right)\left({ }^{\circ}\right)\end{array}$ & $\begin{array}{l}\text { Surface tension } \\
\qquad(\mathrm{mN} / \mathrm{m})^{\mathrm{y}}\end{array}$ \\
\hline $\mathrm{CHAO}$ & Wild type & $-6.2 \pm 0.1$ & $-2.0(0.98)^{\mathrm{Z}}$ & 2.9 & $41 \pm 4$ & $51 \pm 0.7$ \\
\hline CHA1121 & $\Delta m v a T$ & $-7.8 \pm 0.4$ & $-2.6(0.97)$ & 2.9 & $44 \pm 1$ & $53 \pm 0.4$ \\
\hline CHA1126 & $\Delta m v a V$ & $-5.5 \pm 0.6$ & $-2.4(0.95)$ & 3.0 & $37 \pm 2$ & $51 \pm 0.5$ \\
\hline CHA1127 & $\Delta m v a T \Delta m v a V$ & $-6.1 \pm 0.3$ & $-2.1(0.98)$ & 3.0 & $32 \pm 5$ & $30 \pm 0.1$ \\
\hline
\end{tabular}

${ }^{\mathrm{w}}$ Bacteria were grown to the late exponential phase in King's medium B (KMB) broth for $24 \mathrm{~h}$ at $30^{\circ} \mathrm{C}$. Data represent the means \pm standard deviation from three replicates per treatment. The experiments were repeated at least once with similar results.

${ }^{x}$ The possible error made by interpolation (IEP $>2$ ) of the $\zeta$-pH plots is estimated to be 0.2.

$\mathrm{y}$ The surface tension of the growth medium (KMB) was $55 \mathrm{mN} / \mathrm{m}$.

${ }^{\mathrm{z}}$ Data in brackets refer to $R^{2}$ values of linear regression of $n=$ seven consecutive measurements of $\zeta$ in a $\mathrm{pH}$ range of 2.2 to 5.4 .

Table 6. Contribution of MvaT and MvaV to the suppression of Pythium damping-off and root rot disease of cucumber by Pseudomonas fluorescens CHA0 in natural soil ${ }^{x}$

\begin{tabular}{|c|c|c|c|c|c|}
\hline Bacterial strain added ${ }^{y}$ & $\begin{array}{l}\text { Pathogen } \\
\text { treatment }^{\mathrm{y}}\end{array}$ & $\begin{array}{l}\text { Surviving plants } \\
\text { per flask }(\%)\end{array}$ & $\begin{array}{l}\text { Shoot fresh weight } \\
\text { per flask }(\mathrm{g})\end{array}$ & $\begin{array}{l}\text { Root fresh weight } \\
\text { per flask (g) }\end{array}$ & $\begin{array}{c}\text { Colonization by } P \text {. fluorescens } \\
\left(\log _{10} \text { CFU/g of roots }\right)^{\mathrm{z}}\end{array}$ \\
\hline None & - & $100 \mathrm{a}$ & $2.18 \mathrm{a}$ & $0.52 \mathrm{a}$ & ND \\
\hline None & + & $70 \mathrm{~b}$ & $0.69 \mathrm{e}$ & $0.16 \mathrm{e}$ & ND \\
\hline CHA0- $g$ (wild type) & + & $98 \mathrm{a}$ & $1.77 \mathrm{~b}$ & $0.43 \mathrm{~b}$ & $7.91 \pm 0.13$ \\
\hline CHA1121-g $(\Delta m v a T)$ & + & $97 \mathrm{a}$ & $1.53 \mathrm{c}$ & $0.35 \mathrm{c}$ & $7.90 \pm 0.06$ \\
\hline CHA1124 ( $\left(\right.$ mvaT att $\left.\operatorname{Tn} 7-m v a T^{+}\right)$ & + & $98 \mathrm{a}$ & $1.69 \mathrm{~b}$ & $0.39 \mathrm{~b}$ & $7.89 \pm 0.17$ \\
\hline CHA1126- $g(\Delta m v a V)$ & + & $97 \mathrm{a}$ & $1.52 \mathrm{c}$ & $0.35 \mathrm{c}$ & $7.95 \pm 0.14$ \\
\hline CHA1127-g ( & + & $73 \mathrm{~b}$ & $0.96 \mathrm{~d}$ & $0.24 \mathrm{~d}$ & $7.37 \pm 0.16$ \\
\hline CHA1174 ( & + & $93 \mathrm{a}$ & $1.59 \mathrm{bc}$ & $0.38 \mathrm{bc}$ & $7.76 \pm 0.10$ \\
\hline
\end{tabular}

${ }^{x}$ Data represent the means from two individual repetitions of the same experimental setup, with 10 replicates (flasks containing three cucumber plants) per treatment in each experiment. Means within the same column followed by different letters are significantly different $(P \leq 0.05)$ according to Fisher's protected least significant difference (LSD) test. Prior to separation of means by the LSD test, data of the two individual experiments could be pooled following an analysis of variance of trial-by-treatment interactions. ND = not detected.

${ }^{\text {y }}$ P. fluorescens strains were added at $10^{7}$ CFU per gram of natural soil contained within 200-ml flasks (60 g of soil per flask), after planting three $72-\mathrm{h}-\mathrm{old}$, sterile-grown cucumber seedlings per flask. P. ultimum was added as a millet-seed inoculum at $2.5 \mathrm{~g} / \mathrm{kg}$ of soil before planting. Plants were harvested after 7 days. $=+$ with $P$. ultimum.$-=$ without $P$. ultimum.

${ }^{\mathrm{z}}$ The mini-Tn7-gfpl cassette containing a kanamycin resistance determinant (Koch et al. 2001) was introduced as a selective marker into strains CHA0, CHA1121, CHA1126, and CHA1127 to determine their root colonization capacity in natural soil. Strains CHA1124 and CHA1174 could be selectively isolated from roots based on their gentamycin resistance provided by the inserted mini-Tn7-mvaT $T^{+}$cassette. 
tect cucumber from the root disease, as was evident from shoot and root fresh weights that were about 15 and $20 \%$ lower, respectively, than those of plants protected by wild-type strain CHA0 (Table 6). Loss of both MvaT and MvaV function in the double mutant CHA1127 almost completely abolished protection of cucumber against the pathogen, inasmuch as plant survival and plant fresh weights were only marginally higher than those of pathogen-treated control plants (Table 6). Insertion of a single copy of intact mvaT restored biocontrol activity of the mvaT mvaV double mutant to a level similar to that provided by the mvaV mutant (Table 6). In the absence of the pathogenic oomycete, plant growth was not significantly affected by addition of the P. fluorescens strains (data not shown). Root colonization levels at the end of the experiment were similar for all bacterial strains, except for the double mutant CHA1127 in which they were slightly lower (approximately $0.5 \log _{10}$ units) in either the presence (Table 6) or the absence (data not shown) of Pythium ultimum.

A control experiment involving the DAPG-deficient phlA deletion mutant CHA631 (Schnider-Keel et al. 2000), the PLTnonproducing pltC::Tn5 mutant CHA661 (Baehler et al. 2005), and the PLT-negative pltC::Tn5 mvaT mvaV triple mutant CHA1179 (Table 1) was carried out to assess the relative roles of DAPG and PLT in Pythium root-rot suppression. Plant fresh weights in the presence of the pathogen alone were about 3.2-fold lower as compared with plants protected by wild-type CHA0 (average plant fresh weight of $2.09 \pm 0.22 \mathrm{~g}$ per flask). Plant protection levels afforded by the DAPG-negative mutant CHA631 were reduced by more than 30\% (average plant fresh weight of $1.42 \pm 0.24 \mathrm{~g}$ per flask). By contrast, the PLT-negative mutants CHA661 and CHA1179 attained wild-type levels of disease suppression (average plant fresh weights of $2.01 \pm$ $0.17 \mathrm{~g}$ and $2.03 \pm 0.19 \mathrm{~g}$ per flask, respectively), whereas the mvaT mvaV double mutant CHA1127 provided only marginal plant protection.

\section{DISCUSSION}

In the present study, we have identified two novel global regulators of exoproduct formation, motility, and biocontrol activity in the plant-beneficial bacterium $P$. fluorescens CHA0. We have termed the two regulators MvaT and MvaV, owing to their high similarity with members of the emerging family of MvaT-like proteins in Pseudomonas (Diggle et al. 2002; Tendeng et al. 2003) (Fig. 2B). Members of the MvaT family appear to be unique to pseudomonads, and recent evidence establishes them as a novel class of H-NS-related proteins, although they share no sequence homology with any known representative of these nucleoid-associated proteins (Dorman 2004; Tendeng and Bertin 2003; Tendeng et al. 2003). Evidence for relatedness between the MvaT and H-NS families comes from functional and structural analyses in which MvaTlike proteins complement hns mutants of $E$. coli and display domain architectures and DNA-binding properties resembling those of H-NS (Dame et al. 2005; Rescalli et al. 2004; Tendeng et al. 2003). In support of these observations, we found that heterologous expression of mvaT or mvaV of $P$. fluorescens CHA0 in an E. coli hns mutant largely restored typical H-NSdependent phenotypes, such as flagellation, motility, and nonmucoid colony morphology (Table 2), and structural features of MvaT and MvaV were similar to those reported for H-NSlike proteins (Dame et al. 2005; Tendeng et al. 2003).

To date, functional roles for MvaT-like regulators have only been determined for MvaT of $P$. mevalonii as a transcriptional regulator involved in the control of mevalonate catabolism (Rosenthal and Rodwell 1998), MvaT of P. aeruginosa PAO1 as a regulator of different virulence functions (Diggle et al.
2002; Vallet et al. 2004; Westfall et al. 2004), and TurA of $P$. putida KT2440 as an environmental modulator of the $P u$ promoter of the TOL plasmid (Rescalli et al. 2004). Our work lines up with these studies and provides first evidence for a global regulatory role of MvaT-like proteins in plant-associated $P$. fluorescens. This was most evident from the effects of MvaT and MvaV on formation of several exoproducts in strain CHA0, which were particularly pronounced in the case of PLT. Production of this antifungal compound (Fig. 4B) and expression of the corresponding biosynthetic genes (Fig. 3B) were negatively affected by MvaT and, to a lesser extent, by MvaV. Remarkably, the two regulators appear to act in concert, as evidenced by an amplified effect on PLT expression following loss of both MvaT and MvaV function in CHA1127 (Figs. 3B and $4 \mathrm{~B}$ ). In the same vein, effects on levels of other exoproducts, including DAPG, HCN, exoprotease, phospholipase, siderophores, and presumably, biosurfactants were also most pronounced in the mvaT mvaV double mutant (Tables 3 and 5), thus further supporting the idea of a combined global action of the two regulators. Global regulatory effects on exoproduct synthesis have been reported previously for MvaT of $P$. aeruginosa PAO1 (Diggle et al. 2002). Lack of MvaT function in this pseudomonad results in enhanced production of pyocyanin, lectin, and $N$-acylhomoserine lactone signal molecules. A second MvaT-like homolog (i.e., MvaU) of strain PAO1 identified in a follow-up study also acts as a repressor of the formation of lectin and possibly other exoproducts, though its influence is less pronounced than that of MvaT (Vallet al. 2004).

The MvaT-like proteins analyzed so far function mainly as negative regulators of gene expression in Pseudomonas species (Diggle et al. 2002; Rescalli et al. 2004; Vallet et al. 2004). Transcriptional profiling of an mvaT mutant of $P$. aeruginosa PAO1 using DNA microarrays reveals an MvaT-dependent control of at least 150 genes, with more than two-thirds of them being subject to negative regulation by MvaT (Vallet et al. 2004). Likewise, H-NS affects expression of hundreds of genes in E. coli, thereby acting mainly as a repressor of transcription (Atlung and Ingmer 1997; Dorman 2004; Hommais et al. 2001). In P. fluorescens CHA0, the combined effects of MvaT and MvaV on exoproduct formation also often were negative, for instance, in the case of PLT, HCN, exoprotease, biosurfactant (Fig. 4B; Tables 3 and 5), and exopolysaccharide (data not shown) production. Nevertheless, positive control could be observed as well, i.e., for siderophore and phospholipase activity (Table 3 ). This matches the behavior of $P$. aeruginosa MvaT, which has a positive impact on the expression of biosynthetic genes for the siderophore pyochelin and on the production of certain exoenzymes (Diggle et al. 2002; Vallet et al. 2004). The downregulation of phlA expression and, concomitantly, of DAPG biosynthesis in the mvaT mvaV double mutant CHA1127 (Figs. 3A and 4A) may be explained by a disturbed balance of PLT and DAPG levels. In fact, DAPG and PLT exhibit a mechanism of mutual inhibition in which each compound autoinduces its own biosynthesis while repressing the synthesis of the other compound (Baehler et al. 2005; Brodhagen et al. 2004; Schnider-Keel et al. 2000). PLT at a concentration of $100 \mu \mathrm{M}$ strongly represses phlA gene expression in strain CHA0 (Baehler et al. 2005; Schnider-Keel et al. 2000). In the present study, PLT was accumulated to severalfold higher levels in cultures of strain CHA1127, thereby virtually abolishing DAPG production. Absence or low levels of DAPG may then have further stimulated the PLT autoinduction circuit. DAPG production was restored in a PLT-negative pltC mvaT mvaV triple mutant of strain CHA0 (Fig. 5), pointing to a mainly indirect control of DAPG synthesis by MvaT/MvaV.

Surface motility is another trait that was markedly affected by MvaT and MvaV in P. fluorescens CHA0. While MvaT 
alone exerted a negative effect on swimming and swarming activity of strain CHA0, MvaV appeared to exert a significant positive influence on motility only in concert with MvaT (Table 4). The potential differences in functionality of the two proteins are reflected by our finding that MvaT only partially complemented loss of motility to an hns mutant of E. coli, whereas MvaV was able to fully restore this phenotype (Table 2). Previously, the capacity to restore full motility to an hns mutant of E. coli was also reported for an MvaT-like protein of Pseudomonas strain Y1000 (Tendeng et al. 2003). Overexpression of the $m v a T$-like gene from an oligocopy plasmid in strain Y1000 resulted in reduced motility (Tendeng et al. 2003), thus supporting our finding of enhanced motility in the mvaT mutant of P. fluorescens CHA0. By contrast, surface motility was reduced in an mvaT mutant of $P$. aeruginosa (Diggle et al. 2002), indicating considerable functional diversity among MvaT-like proteins with respect to motility control in pseudomonads. Loss of motility and flagellation is a common phenotype of hns mutants of E. coli (Bertin et al. 1994; Hommais et al. 2001; Soutourina et al. 2002). It has been speculated that negative effects of H-NS on repressors of flagella synthesis and function may account for loss of motility (Dorman 2004). Reduced swimming and swarming motilities in the mvaT mvaV mutant CHA1127 may not be explained by a loss of flagellation, since electron microscopic analysis showed that the strain still possessed wild-type numbers of flagella; yet, we cannot exclude potential effects on efficiency of flagellar function. Since motility and adhesion of pseudomonads on surfaces is influenced by biosurfactants and physicochemical cell surface properties (Andersen et al. 2003; Déziel et al. 2003; Kuiper et al. 2004; Redman et al. 2004), we checked whether changes in these characteristics may have been a reason for the reduced motility of the mvaT mvaV double mutant. However, the enhanced biosurfactant activity and the minimal differences in cell surface charge, cell surface hydrophobicity, and other physicochemical characteristics of the mutant compared with the wild type (Table 5) cannot explain the motility defect on agar surfaces (Table 4). Rather, it may be speculated that loss of MvaT and MvaV function may have led to a significant production of polysaccharides at the outermost cell wall and concomitantly to attractive steric polymer interactions, as described by Jucker and associates (1998). The lowered contact angle of the mutant CHA1127 may be an indicator for the presence of such outer cell wall components.

In plant assays carried out in natural soil, inactivation of mvaT or mvaV in P. fluorescens CHA0 resulted in a partial loss of biocontrol activity against a root disease of cucumber caused by Pythium ultimum (Table 6). Reduction of plant protective ability was most pronounced in an mvaT mvaV double mutant. Drastically lowered levels of DAPG production entailed by massive PLT production in the double mutant (discussed above) may have accounted, at least in part, for this effect. Accordingly, DAPG production and biocontrol activity could be restored to wild-type levels when PLT production was abolished in this mutant. Evidence for an important role of DAPG in the suppression of this cucumber disease comes from our control experiments, in which the biocontrol effect of a DAPG-deficient mutant of strain CHA0 was strongly reduced whereas a PLT-nonproducing mutant provided wild-type levels of control, confirming previous findings of Maurhofer and associates (1994). It remains to be seen whether PLT overproduction in the double mutant could be beneficial in certain plant-pathogen combinations. Our previous findings indicate that enhanced antibiotic production in $P$. fluorescens may result in either positive or negative effects on disease suppression, depending on the plant host (Maurhofer et al. 1992; Maurhofer et al. 1995; Schnider et al. 1995). It has also to be kept in mind that kinetics of PLT and DAPG gene expression may vary considerably on different plant hosts (Kraus and Loper 1995; Maurhofer et al. 2004; Notz et al. 2001). However, due to the global nature of regulatory effects of MvaT-like proteins (discussed above; Diggle et al. 2002; Vallet et al. 2004), defects in biocontrol capacity may not only be related to the presence or absence of a particular metabolite such as DAPG or PLT. In our study, this is illustrated by the reduced protection levels afforded by the mvaT or mvaV single mutants, which can not be explained by effects on DAPG production, since biosynthesis of the compound is not grossly affected in these strains (Fig. 4A). In our study, root colonization levels attained by $P$. fluorescens wild-type CHA0 and mutants defective for MvaT and $\mathrm{MvaV}$ were largely similar. Efficient root colonization is considered to be a basic prerequisite for biocontrol efficacy (Chin-A-Woeng et al. 2003; Lugtenberg et al. 2001). In view of the important role of MvaT in biofilm formation in P. aeruginosa (Vallet et al. 2004; Vallet-Gely et al. 2005), it may be interesting to examine more closely potential effects of the $P$. fluorescens MvaT-like regulators on root colonization patterns in the presence and absence of fungal pathogens.

Exoproduct synthesis, motility, and biocontrol activity were most affected in an mvaT mvaV double mutant of $P$. fluorescens CHA0, suggesting a combined action of MvaT and MvaV. At the present stage, it is difficult to deduce a precise mechanism for the functioning of the two regulators. In a possible scenario, MvaT and MvaV may be interchangeable to some extent, i.e., one regulator may, at least partly, compensate for the loss of the other. This is illustrated by the usually mild or nonexistent effects induced by the lack of one of the regulators and the drastic changes, including induction (exoproduct synthesis), amplification (exoproduct synthesis, biocontrol activity), and inversion (motility) of effects caused by the loss of both regulators. The potential interchangeability of the two regulators may also be reflected by a highly conserved amino acid sequence in the C-terminal region of MvaT and MvaV, which appears to be present in all proteins of the MvaT family (Fig. 2B) and is likely to have an important functional role. In $\mathrm{H}-\mathrm{NS}$, the C-terminal domain has DNA-binding function, whereas the $\mathrm{N}$-terminal domain has oligomerization activity that provides the protein not only with the ability to self-associate but also to form heteromers with other H-NS related proteins (Atlung and Ingmer 1997; Dorman 2004; Rimsky 2004; Tendeng and Bertin 2003). H-NS has the ability to form bridges between adjacent tracts of DNA, a mechanism relevant not only for DNA compaction but also for transcription regulation (Dame et al. 2005; Dorman 2004). Remarkably, the domain structures (Rescalli et al. 2004; Tendeng et al. 2003) and DNA-binding properties (Dame et al. 2005) of MvaT proteins largely resemble that of $\mathrm{H}-\mathrm{NS}$. Moreover, the potential of MvaT proteins to form homomeric or heteromeric complexes and to interact with promoter regions is illustrated by studies of Vallet-Gely and associates (2005), Rosenthal and Rodwell (1998), and Westfall and associates (2004). Interestingly, most of the Pseudomonas species analyzed so far possess at least two, sometimes three or even more MvaT-like proteins (Diggle et al. 2002; Rescalli et al. 2004; Tendeng and Bertin 2003; Tendeng et al. 2003; Vallet et al. 2004) (Fig. 2B). Based on these observations, it is tempting to speculate that pseudomonads such as strain CHA0 may use multiple MvaT homologs to share, partition, or amplify various regulatory functions in response to environmental and physiological signals.

In conclusion, our work establishes the two H-NS-related proteins MvaT and MvaV as novel global regulators of exoproduct formation, motility, and biocontrol activity in plantassociated $P$. fluorescens CHA0. This adds a novel set of regulatory elements to the growing list of global regulators involved 
in the control of these relevant traits in biocontrol pseudomonads, comprising the sigma factors RpoD, RpoS, and RpoN (Haas and Keel 2003; Péchy-Tarr et al. 2005; Sarniguet et al. 1995; Schnider et al. 1995) and components of a posttranscriptional control machinery piloted by the GacS/GacA two-component system (Haas and Défago 2005). In future work, it may be worthwhile to investigate potential molecular interactions between the MvaT-like proteins and other elements of the complex regulatory network that controls beneficial activity in biocontrol pseudomonads.

\section{MATERIALS AND METHODS}

\section{Microorganisms, plasmids, and culture conditions.}

The bacterial strains and plasmids used in this study are described in Table 1. P. fluorescens strains were cultivated on $\mathrm{NA}$, on $\mathrm{KMB}$, in KMB broth, in KMB malt broth (containing, per liter: malt extract [Oxoid, Basingstoke, U.K.], 7.5 g; proteose peptone No. 2 [Difco, Becton Dickinson, Franklin Lakes, NJ, U.S.A.], $10 \mathrm{~g}$; glycerol $87 \%$ [wt/vol], $5 \mathrm{~g} ; \mathrm{MgSO}_{4} \times$ $7 \mathrm{H}_{2} \mathrm{O}, 0.75 \mathrm{~g} ; \mathrm{K}_{2} \mathrm{HPO}_{2} \times 3 \mathrm{H}_{2} \mathrm{O}, 0.75 \mathrm{~g}$ ), and in LB broth (Baehler et al. 2005; Sambrook and Russell 2001) at $30^{\circ} \mathrm{C}$, unless otherwise specified. E. coli strains were grown on NA and in $\mathrm{LB}$ at $37^{\circ} \mathrm{C}$. Antimicrobial compounds, when required, were added to the growth media at the following concentrations: ampicillin sodium salt, $100 \mu \mathrm{g} / \mathrm{ml}$; chloramphenicol, 25 $\mu \mathrm{g} / \mathrm{ml}$; gentamicin sulphate, $10 \mu \mathrm{g} / \mathrm{ml}$; kanamycin sulphate, 50 $\mu \mathrm{g} / \mathrm{ml}$; tetracycline hydrochloride, $25 \mu \mathrm{g} / \mathrm{ml}$ for $E$. coli and $125 \mu \mathrm{g} / \mathrm{ml}$ for $P$. fluorescens strains. When appropriate, 5bromo-4-chloro-3-indolyl- $\beta$-D-galactoside (X-Gal) was incorporated into solid media to monitor $\beta$-galactosidase expression (Sambrook and Russell 2001). The plant-pathogenic oomycete P. ultimum 67-1 was cultured on malt agar and, for use in plant disease suppression assays, on autoclaved millet seeds as described previously (Maurhofer et al. 1992).

\section{DNA manipulations and sequence analyses.}

Chromosomal DNA of $P$. fluorescens was isolated as described previously (Schnider-Keel et al. 2000). Small- and largescale plasmid preparations were performed with the cetyltrimethylammonium bromide method (Sambrook and Russel 2001) or the Jetstar 2.0 kit (Genomed, Basel, Switzerland). Standard techniques were used for restriction, agarose gel electrophoresis, dephosphorylation, generation of blunt ends with T4 DNA polymerase (Boehringer, Ingelheim, Germany), isolation of DNA fragments from low melting-point agarose gels, and ligation (Sambrook and Russell 2001; Schnider-Keel et al. 2000, 2001). Restriction fragments were purified from agarose gels using the MinElute gel extraction or QIAquick gel extraction kits (Qiagen, Basel, Switzerland), depending on the size of the fragment. Electroporation of bacterial cells with plasmid DNA was done as described previously (Schnider-Keel et al. 2000). Polymerase chain reactions were carried out using the Expand high fidelity PCR system (Roche, Basel, Switzerland), following procedures detailed elsewhere (Baehler et al. 2005; Péchy-Tarr et al. 2005). Nucleotide sequences were determined on both strands with the Big Dye terminator cycle sequencing kit 1.1 (Perkin-Elmer, Fremont, CA, U.S.A.) and an ABI-Prism 373 automatic sequencer (Applied Biosystems, Foster city, CA, U.S.A.) and in part by Microsynth (Balgach, Switzerland). Nucleotide and deduced amino acid sequences were analyzed with programs of the European Molecular Biology Open Software Suite. Sequence alignments were performed using Clustal W (Thompson et al. 1994). Phylogenetic analyses using the neighbor-joining method with the Nei-Kumar gamma parameter correction of evolutionary distances were carried out with MEGA version 2.1 software (Kumar et al. 2001).
Transposon mutagenesis and localization of Tn5 insertions.

To screen for novel regulators of antibiotic production, strain CHA250/pME7109 was subjected to random Tn5 insertion mutagenesis using $E$. coli $\mathrm{W} 3110$ containing the Tn5 suicide plasmid pLG221 (Boulnois et al. 1985) as the donor strain, following a method described by Maurhofer and associates (1994). Strain CHA250/pME7109 is an rpoN in framedeletion mutant of $P$. fluorescens CHA0 (Péchy-Tarr et al. 2005) harboring a pltA-gfp reporter fusion on plasmid pME7109 (Table 1) (Baehler et al. 2005). The expression of pltA is strongly repressed in the $r p o N$ mutant (Péchy-Tarr et al. 2005). Approximately 3,500 tetracycline-, kanamycin-, and chloramphenicol-resistant $P$. fluorescens colonies carrying Tn5 were transferred to 96-well black microtitre plates with flat transparent bottoms (Greiner Bio-one, Frickenhausen, Germany) containing $\mathrm{KMB}$ broth and were assayed for green fluorescence at the mid-exponential and early stationary-growth phases, using procedures described in detail below (assay for expression of DAPG and PLT biosynthetic genes). Mutants in which plt-gfp expression was significantly increased compared with the parental strain were reanalyzed in greater detail and the Tn5 insertion site was determined using an arbitrary PCR method described by O'Toole and Kolter (1998). Briefly, a first amplification round was carried out using an arbitrary primer (ARB1) and a primer specific to the right end of Tn5 (Tn5Ext). In a second amplification round, the first-round PCR product was used as a template for amplification with primers ARB2 (identical to the $5^{\prime}$ end of ARB1) and Tn5Int (specific to the rightmost end of Tn5). The resulting fragments were cloned into the pGEM-T Easy vector (Table 1) and sequenced, and the DNA sequences obtained were compared with existing genomic data using the BLASTN program.

\section{Cloning of the mvaT and mvaV genes from $P$. fluorescens.}

The mvaT gene and its surroundings were amplified from $P$. fluorescens CHA0 using primers MvaTA and MvaTC. To amplify the mvaV gene and adjacent chromosomal regions from CHA0, primers MvaVPA and MvaVPB were used. Primers were designed based on genomic data available for the very closely related $P$. fluorescens Pf-5 (Paulsen et al. 2005). For mvaT, the PCR amplification yielded a 2.2-kb band. The PCR product was digested with EcoRI and HindIII and was cloned into vector pUK21 to give pME7130 (Fig. 1A; Table 1). For $m v a V$, the PCR amplification produced a $2.3-\mathrm{kb}$ fragment that was digested with EcoRI and XmaI and was cloned into pUK21 to give pME7140 (Fig. 1B; Table 1). For both constructs, the inserts of three of the obtained clones were sequenced to confirm the identity of the cloned fragments.

\section{Construction of mvaT and mvaV \\ in frame-deletion mutants of $\boldsymbol{P}$. fluorescens.}

To generate the mvaT mutant CHA1121, a 351-bp fragment was deleted in-frame in the mvaT gene (Fig. 1A). For this purpose, an 831-bp fragment including the first four codons of mvaT and the adjacent upstream chromosomal region was amplified by PCR from P. fluorescens CHA0, using primers P5 and P6. An 825-bp EcoRI-XbaI fragment including the last four codons of mvaT and the adjacent downstream region was amplified by PCR with primers P7 and P8. The resulting upstream and downstream fragments were digested with KpnI and EcoRI and with EcoRI and $X b a \mathrm{I}$, respectively, and were cloned by a triple ligation into pUK21 digested with KpnI and XbaI, giving plasmid pME7131 (Table 1). The 1.66-kb KpnI$X b a I$ insert in pME7131 was checked by sequencing and was excised and cloned into the suicide plasmid pME3087 digested with KpnI-XbaI, producing pME7132 (Fig. 1A). To obtain the $\Delta$ mvaT mutant CHA1121 (Fig. 1A; Table 1), the suicide plas- 
mid pME7132 was then integrated into the chromosome of strain CHA0 by triparental mating, using $E$. coli HB101/pME497 as the mobilizing strain, with selection for tetracycline- and chloramphenicol-resistant recombinants (Schnider-Keel et al. 2000, 2001). Excision of the vector by a second crossing-over occurred after enrichment for tetracycline-sensitive cells.

An analogous gene replacement strategy was followed to create the 351-bp mvaV in-frame deletion in CHA1126 (Fig. 1B). Using CHA0 DNA as a template, two fragments including the first and the last four codons of the mvaV gene and the respective up- and downstream flanking regions were amplified by PCR with primers P21 plus P22 and P23 plus P24, respectively. The 967-bp upstream and 1,000-bp downstream fragments obtained were digested with SmaI and EcoRI and with $E c o$ RI and $X b a \mathrm{I}$, respectively, and were cloned by a triple ligation into SmaI- and XbaI-digested pUK21. The identity of the insert in the resulting plasmid pME7135 (Table 1) was checked by sequencing. The 1.97-kb SmaI-XbaI fragment was then excised from pME7135 and was cloned into pME3087 digested with the same restriction enzymes, giving plasmid pME7136 (Fig. 1B). The suicide plasmid pME7136 then served to delete the mvaV gene in CHA0, creating CHA1126 (Fig. 1B; Table 1).

The $\Delta m v a T$ minaV double mutant CHA1127 and the $\Delta$ mvaT $\Delta$ rpoN mutant CHA1122 (Table 1) were obtained by using the suicide plasmid pME7132 to delete the mvaT genes in the mvaV mutant CHA1126 and in the rpoN mutant CHA250, respectively. Likewise, pME7132 and pME7136 were used to delete mvaT and mvaV in the pltC::Tn5 mutant CHA661, generating the PLT-negative $\Delta m v a T \Delta m v a V$ triple mutant CHA1179 (Table 1). The mvaT and mvaV mutations were verified by PCR (data not shown).

\section{Complementation of $\mathrm{mvaT}$ and $\mathrm{mvaV}$ mutations.}

To complement strain CHA1121 ( $\Delta$ mvaT), monocopy parental mvaT was introduced into the chromosome using a miniTn7 delivery system (Schnider-Keel et al. 2000). For this purpose, a 795-bp fragment, encompassing mvaT, the 521-bp upstream intergenic region, and the first 32 bp of ORFA (Fig. 1A) was amplified by PCR from $P$. fluorescens CHA0 with primers MvaTcompl3 and MvaTcompl2, was digested with HindIII and KpnI, and was cloned into the mini-Tn7-Gm carrier plasmid pME6182 (Péchy-Tarr et al. 2005). The construct obtained, pME7133 (Fig. 1A), and the Tn7 transposition helper plasmid pUX-BF13 (Bao et al. 1991) were coelectroporated into the recipient strain CHA1121. A similar approach was taken to introduce the mvaV gene as a single copy into the unique Tn7 attachment site of the $\Delta m v a V$ mutant CHA1126. Using CHA0 DNA as a template, a 797-bp fragment containing $m v a V$, the 233-bp upstream intergenic region, and the last 34 codons of ORFC (Fig. 1B) was amplified with primers MvaVcompl3 and MvaVcompl4. The PCR product was digested with HindIII and KpnI and was cloned into pME6182 to give pME7142 (Fig. 1B). The mini-Tn7-mvaT and miniTn7-mvaV constructs on pME7133 and pME7142, respectively, were also used to transform the mvaT mvaV double mutant CHA1127. The single Tn7-mvaT insertion in strains CHA1124 and CHA1174, and the Tn7-mvaV ${ }^{+}$insertion in strains CHA1176 and CHA1177 (Table 1) were checked by PCR using primers PTn7Gm and PTn7glmS (data not shown).

\section{Assessment of growth characteristics} of the $P$. fluorescens mvaT and mvaV mutants.

Growth rates for $P$. fluorescens $\mathrm{CHA} 0$ and its mutant derivatives were monitored in different rich media, including LB and $\mathrm{KMB}$ broth, and in the minimal media OSG and OSGly
(Baehler et al. 2005; Schnider-Keel et al. 2000). Bacterial cells from overnight LB cultures were washed, and aliquots of $20 \mu \mathrm{l}$ of the cell suspensions were adjusted to an optical density at $600 \mathrm{~nm}\left(\mathrm{OD}_{600}\right)$ of 1.0 were used to inoculate $20 \mathrm{ml}$ of medium contained within 100-ml flasks plugged with cellulose stoppers. Cultures were incubated with rotational shaking at $180 \mathrm{rpm}$ at $30^{\circ} \mathrm{C}$. Doubling times of strain CHA0 and its derivatives were calculated from $\mathrm{OD}_{600}$ values recorded from triplicate cultures during exponential growth (Péchy-Tarr et al. 2005; Schnider-Keel et al. 2001).

Assay for expression of DAPG and PLT biosynthetic genes.

$P$. fluorescens $\mathrm{CHA} 0$ and its mutant derivatives carrying a phlA-gfp fusion on plasmid pME7100 or a pltA-gfp fusion on pME7109 (Baehler et al. 2005; Table 1) were grown in OSGly, $\mathrm{KMB}$, or KMB malt medium without selective antibiotics in 96-well black microtitre plates with flat transparent bottoms. For the assay, $10 \mathrm{ml}$ of the respective medium was inoculated with $20 \mu \mathrm{l}$ of exponential-growth phase LB cultures of the bacterial strains diluted to an $\mathrm{OD}_{600}=0.01$. For each treatment, eight wells of the microtitre plate were then partially filled with aliquots of $200 \mu \mathrm{l}$ of the respective bacterial culture. Cultures were incubated at $30^{\circ} \mathrm{C}$ with orbital shaking at $500 \mathrm{rpm}$ in a Thermostar incubator (BMG Labtechnologies, Offenburg, Germany). In all experiments, $\mathrm{OD}_{600}$ (growth) and green fluorescence (excitation at $480 \mathrm{~nm}$ and emission at $520 \mathrm{~nm}$ ) was measured with a Fluostar fluorescence microplate reader (BMG Labtechnologies) throughout the exponential- and stationary-growth phases (Baehler et al. 2005). For each individual measurement, the green fluorescence value was divided by the corresponding $\mathrm{OD}_{600}$ value giving the specific fluorescence of the cells expressed as relative fluorescence units (Baehler et al. 2005). The green fluorescence emitted by cells of wild-type strain CHA0 without $g f p$ reporter fusion was determined for background correction.

\section{Quantification of exoproducts.}

PLT production was assessed for bacteria grown in 300-ml Erlenmeyer flasks with $100 \mathrm{ml}$ of KMB broth. For inoculation, $3-\mathrm{ml}$ aliquots of overnight LB cultures of the bacterial strains adjusted to an $\mathrm{OD}_{600}=2.0$ were used. Cultures were incubated at $30^{\circ} \mathrm{C}$ with orbital shaking at $180 \mathrm{rpm}$. For monitoring production of DAPG and monoacetylphloroglucinol, bacteria were grown in KMB malt broth. A loop-full of cells from a colony grown on $\mathrm{NA}$ at $30^{\circ} \mathrm{C}$ for $24 \mathrm{~h}$ was used for inoculation of $100 \mathrm{ml}$ of medium, and cultures were incubated at $27^{\circ} \mathrm{C}$ with orbital shaking at $150 \mathrm{rpm}$. DAPG, PLT, and monoacetylphloroglucinol were extracted from acidified cultures with ethyl acetate and were quantified by established high-performance liquid chromatography procedures (Keel et al. 1992; Maurhofer et al. 1992, 1994). HCN production was measured colorimetrically in samples from oxygen-limited cultures in KMB broth, as previously described by Voisard and associates (1989). Bacteria were grown in sealed 125-ml bottles containing $60 \mathrm{ml}$ of medium that had been inoculated with $100 \mu \mathrm{l}$ of an overnight $\mathrm{LB}$ culture adjusted to an $\mathrm{OD}_{600}=1.0$. Cultures were incubated at $30^{\circ} \mathrm{C}$ with rotational shaking at $180 \mathrm{rpm}$ for $24 \mathrm{~h}$. For assessing production of siderophores, aliquots of 10 $\mu$ l of overnight LB cultures were spotted on chrome azurol $\mathrm{S}$ plates (Schwyn and Neilands 1987). After incubation at $30^{\circ} \mathrm{C}$ for $24 \mathrm{~h}$, siderophore production was scored by measuring the diameter of orange halos appearing around the bacterial spots. Phospholipase activity was detected on Columbia agar (Oxoid) supplemented with 3\% blood, and exoprotease activity was examined on skim-milk agar (Sacherer et al. 1994). For inoculation, $10 \mu \mathrm{l}$ of overnight LB cultures (adjusted to an $\mathrm{OD}_{600}=$ 1.0) were spotted on the plates. Enzymatic activity was as- 
sessed after a 30 -h incubation period at $30^{\circ} \mathrm{C}$ by measuring the diameter of the clear halos appearing around bacterial growth. Exoprotease activity was also determined in cell-free supernatants from bacterial cultures incubated at $30^{\circ} \mathrm{C}$ for $16 \mathrm{~h}$ in 20 $\mathrm{ml}$ of KMB broth contained in a 100-ml flask, using an azocasein assay described in detail by Valverde and associates (2004). In this colorimetric assay, one exoprotease activity unit (P.U.) was defined as follows: 1 P.U. $=(\mathrm{A} 440 \times$ $1,000) /($ incubation time $[\mathrm{h}] \times$ sample volume $[\mathrm{ml}] \times \mathrm{A} 600)$. Mucoid colony phenotypes indicative of copious exopolysaccharide production (Schnider-Keel et al. 2001) were detected after overnight growth of bacteria on NA plates.

\section{Motility assays.}

Surface motility of $P$. fluorescens strains was tested as described previously by Péchy-Tarr and associates (2005). Flagellar swimming was checked on plates containing (wt/vol) $0.3 \%$ agar (Serva, Wallisellen, Switzerland), $1 \%$ yeast extract (Difco), $1 \%$ tryptone (Difco), and $1.25 \% \mathrm{NaCl}$. Swarming motility was examined on plates containing (wt/vol) $0.5 \%$ agar, $0.8 \%$ nutrient broth (Difco), and $0.5 \%$ glucose. Twitching motility was assayed on LB broth solidified with $1 \%$ agar. Swarming motility of $E$. coli strains was determined as described by Bertin and associates (1994), using tryptone swarm plates that contained $0.3 \%$ Bacto agar (Difco), $1 \%$ tryptone (Difco), and $0.5 \% \mathrm{NaCl}$. For inoculation of swim and swarm plates, cells from bacterial overnight cultures on NA were placed on the agar surface in the center of the plates, using a sterile toothpick. For twitch plates, cells were stab-inoculated to the bottom of the petri dish. In all assays, motility was scored as the diameter of bacterial displacement from the point of inoculation after 24 and $48 \mathrm{~h}$ (swim and swarm plates) and 5 days (twitch plates) of incubation at room temperature for $P$. fluorescens and at $30^{\circ} \mathrm{C}$ for $E$. coli. To confirm the presence or absence of flagella, bacterial cells taken from the edge of swarm colonies were examined by transmission electron microscopy as described by Péchy-Tarr and associates (2005).

\section{Determination of surface tension and emulysifying activity of culture supernantants.}

Cell-free culture supernatants were prepared from bacteria grown in $\mathrm{KMB}$ broth for $24 \mathrm{~h}$ at $30^{\circ} \mathrm{C}$. Surface tensions of cell-free culture supernatants were measured with a plate device (Lauda Tensiometer TD 1, Lauda Dr. Wobster GmbH, Lauda Königshofen, Germany) according to the Wilhelmy technique (Adamson 1976). Culture supernatants were tested for emulsifying activity using the toluene-water mixing assay described in detail by Kuiper and associates (2004). Briefly, $1 \mathrm{ml}$ of toluene was thoroughly vortexed through $1 \mathrm{ml}$ of supernatant. The mixture was then incubated at room temperature, and phases that formed were checked for turbidity after $15 \mathrm{~min}$ and $1 \mathrm{~h}$. In all assays, sterile KMB broth served as a control.

\section{Characterization of bacterial cell surface properties.}

Physico-chemical cell surface properties of bacteria grown in $\mathrm{KMB}$ broth at $30^{\circ} \mathrm{C}$ were investigated using standard methods as described elsewhere (van Looosdrecht et al. 1987). The electrophoretic mobility $(\mu)$ of bacterial suspensions in $10 \mathrm{mM}$ $\mathrm{KNO}_{3}$ at $\mathrm{pH} 6.2$ was determined in a Doppler electrophoretic light scattering analyzer (Zetasizer Nano ZS, Malvern Instruments Ltd., Malvern, Worcestershire, U.K.) at 100 V. The $\zeta$ as an indirect measure of cell surface charge was approximated from the electrophoretic mobility according to the method of Helmholtz-von Smoluchowski (Hiementz 1986). The IEP of bacteria was determined from $\zeta$-pH plots obtained by measuring $\mu$ in $0.01 \mathrm{M} \mathrm{HNO}_{3} / \mathrm{KNO}_{3}$ solutions with $\mathrm{pH}$ varying between 2 and 5.5, using a MPT-2 autotitrator (Malvern Instru- ments Ltd.). Bacterial lawns needed for $\theta_{\mathrm{w}}$ measurements were prepared by collecting cell suspensions in $10 \mathrm{mM}$ phosphatebuffered saline on $0.45-\mu \mathrm{m}$ pore size Micropore filters (Schleicher \& Schuell, Dassel, Germany), mounting the filters on glass slides, and drying them for $2 \mathrm{~h}$ at room temperature. Cell-surface hydrophobicities were derived from $\theta_{\mathrm{w}}$ of water drops on the bacterial lawns using a Krüss drop shape analysis system DSA 100 (Krüss GmbH, Hamburg, Germany) (van Loosdrecht et al. 1987). According to an earlier classification, cells exhibiting contact angles of $\theta_{\mathrm{w}}<20^{\circ}, 20^{\circ} \leq \theta \leq 50^{\circ}$, and $\theta_{\mathrm{w}}>50^{\circ}$ are hydrophilic, intermediately hydrophilic and hydrophobic, respectively (Rijnaarts et al. 1995).

\section{Plant disease suppression and root colonization assays.}

For the biocontrol assays, 200-ml Erlenmeyer flasks with wide openings were partially filled with $60 \mathrm{~g}$ of natural sandy loam soil from Eschikon, Switzerland (Keel et al. 2002). When appropriate, the soil was artificially infested with $2.5 \mathrm{~g}$ of a five-day-old millet-seed inoculum of $P$. ultimum 67-1 per kilogram (Keel et al. 2002; Maurhofer et al. 1992). Three sterilegrown, 72-h-old cucumber seedlings (Cucumis sativus cv. Chinese Snake) were then placed in each flask, as previously described (Keel et al. 2002). P. fluorescens strains were added to soil as a suspension ( $5 \mathrm{ml}$ per flask) of cells washed twice in sterile distilled water to give $1 \times 10^{7} \mathrm{CFU}$ per gram of soil. Control flasks received the same amount of sterile water. Seedlings were covered with nontreated soil and flasks were sealed with cotton stoppers. The microcosms were incubated in a growth chamber containing $80 \%$ relative humidity and $22^{\circ} \mathrm{C}$ with light $\left(200 \mu \mathrm{mol} \mathrm{s} \mathrm{m}^{-1} \mathrm{~m}^{-2}\right.$; ratio of 1.37 of light at 660 to $730 \mathrm{~nm}$ ) for $16 \mathrm{~h}$, followed by an 8 -h dark period at $15^{\circ} \mathrm{C}$. After six days of incubation, plants were removed from the flasks, were washed and briefly dried with paper towels, and were weighed. Roots from each flask were pooled and transferred into $50-\mathrm{ml}$ plastic tubes containing $10 \mathrm{ml}$ of sterile distilled water. Tubes were vigorously shaken at $240 \mathrm{rpm}$ for 30 min, and the resulting suspensions were used to determine CFU numbers. Data represent the means from two individual repetitions of the same experiment with ten replicates per treatment in each experiment, with one replicate corresponding to one flask containing three cucumber plants. Data of both experiments together were first analyzed for trial-by-treatment interaction by analysis of variance using Systat version 10.0 (Systat Inc., Evanston, IL, U.S.A.). Analysis of variance indicated that data from the two different trials could be pooled (Table 6). Means were separated with Fisher's protected least significant difference test $(P \leq 0.05)$. Data for CFU counts were $\log _{10}$-transformed prior to statistical analysis.

\section{ACKNOWLEDGMENTS}

We thank M. Bottiglieri, L. Rochat, R. Pai, R. Remer (Umweltforschungszentrum Leipzig [UFZ]), B. Würz (UFZ), and J. Reichenbach (UFZ) for help with some of the experiments and L. Guy for advice with phylogenetic analyses. We thank M. Adrian (Laboratoire d'Analyse Ultrastructurale, Université de Lausanne) for electron microscopy and P. N. Bertin (Université Louis Pasteur/CNRS, Strasbourg, France) for providing E. coli FB8 and BE1410. We gratefully acknowledge financial support from the Swiss National Science Foundation (projects 3100-061360 and 3100A0105881).

\section{LITERATURE CITED}

Abbas, A., Morrissey, J. P., Marquez, P. C., Sheehan, M. M., Delany, I. R., and O'Gara, F. 2002. Characterization of interactions between the transcriptional repressor PhlF and its binding site at the phlA promoter in Pseudomonas fluorescens F113. J. Bacteriol. 184:3008-3016.

Adamson, A. W. 1976. Physical chemistry of surfaces, 3rd ed. John Wiley \& Sons, New York 
Andersen, J. B., Koch, B., Nielsen, T. H., Sorensen, D., Hansen, M., Nybroe, O., Christophersen, C., Sorensen, J., Molin, S., and Givskov, M. 2003. Surface motility in Pseudomonas sp. DSS73 is required for efficient biological containment of the root-pathogenic microfungi Rhizoctonia solani and Pythium ultimum. Microbiology 149:37-46.

Atlung, T., and Ingmer, H. 1997. H-NS: A modulator of environmentally regulated gene expression. Mol. Microbiol. 24:7-17.

Baehler, E., Bottiglieri, M., Péchy-Tarr, M., Maurhofer, M., and Keel, C. 2005. Use of green fluorescent protein-based reporters to monitor balanced production of antifungal compounds in the biocontrol agent Pseudomonas fluorescens CHA0. J. Appl. Microbiol. 99:24-38.

Bangera, M. G., and Thomashow, L. S. 1999. Identification and characterization of a gene cluster for synthesis of the polyketide antibiotic 2,4-diacetylphloroglucinol from Pseudomonas fluorescens Q2-87. J. Bacteriol. 181:3155-3163.

Bao, Y., Lies, D. P., Fu, H., and Roberts, G. P. 1991. An improved Tn7based system for the single-copy insertion of cloned genes into chromosomes of gram-negative bacteria. Gene 109:167-168.

Bertin, P., Terao, E., Lee, E. H., Lejeune, P., Colson, C., Danchin, A., and Collatz, E. 1994. The H-NS protein is involved in the biogenesis of flagella in Escherichia coli. J. Bacteriol. 176:5537-5540.

Boulnois, G. J., Varley, J. M., Sharpe, G. S., and Franklin, F. C. H. 1985. Transposon donor plasmids, based on ColIb-P9, for use in Pseudomonas putida and a variety of other gram negative bacteria. Mol. Gen. Genet. 200:65-67.

Brodhagen, M., Henkels, M. D., and Loper, J. E. 2004. Positive autoregulation and signaling properties of pyoluteorin, an antibiotic produced by the biological control organism Pseudomonas fluorescens Pf-5. Appl. Environ. Microbiol. 70:1758-1766.

Buell, C. R., Joardar, V., Lindeberg, M., Selengut, J., Paulsen, I. T., Gwinn, M. L., Dodson, R. J., Deboy, R. T., Durkin, A. S., Kolonay, J. F., Madupu, R., Daugherty, S., Brinkac, L., Beanan, M. J., Haft, D. H., Nelson, W. C., Davidsen, T., Zafar, N., Zhou, L., Liu, J., Yuan, Q., Khouri, H., Fedorova, N., Tran, B., Russell, D., Berry, K., Utterback, T., Van Aken, S. E., Feldblyum, T.V., D'Ascenzo, M., Deng, W.-L., Ramos, A. R., Alfano, J. R., Cartinhour, S., Chatterjee, A. K., Delaney, T. P., Lazarowitz, S. G., Martin, G. B., Schneider, D. J., Tang, X., Bender, C. L., White, O., Fraser, C. M., and Collmer, A. 2003. The complete genome sequence of the Arabidopsis and tomato pathogen Pseudomonas syringae pv. tomato DC3000. Proc. Natl. Acad. Sci. U.S.A. 100:1018110186.

Chin-A-Woeng, T. F., Bloemberg, G. V., and Lugtenberg, B. J. J. 2003. Phenazines and their role in biocontrol by Pseudomonas bacteria. New Phytol. 157:503-523.

Combet, C., Blanchet, C., Geourjon, C., and Deléage, G. 2000. NPS@: Network protein sequence analysis.Trends Biochem. Sci. 25:147-150.

Dame, R. T., Luijsterburg, M. S., Krin, E., Bertin, P. N., Wagner, R., and Wuite, G. J. L. 2005. DNA bridging: A property shared among H-NSlike proteins. J. Bacteriol. 187:1845-1848.

Déziel, E., Lépine, F., Milot, S., and Villemur, R. 2003. rhlA is required for the production of a novel biosurfactant promoting swarming motility in Pseudomonas aeruginosa: 3-(3-hydroxyalkanoyloxy)alkanoic acids (HAAs), the precursors of rhamnolipids. Microbiology 149:2005-2013.

Diggle, S. P., Winzer, K., Lazdunski, A., Williams, P., and Camara, M. 2002. Advancing the quorum in Pseudomonas aeruginosa: MvaT and the regulation of $\mathrm{N}$-acylhomoserine lactone production and virulence gene expression. J. Bacteriol. 184:2576-2586.

Dorman, C. J. 2004. H-NS: A universal regulator for a dynamic genome. Nature Rev. Microbiol. 2:391-400.

Duffy, B. K., and Défago, G. 1999. Environmental factors modulating antibiotic and siderophore biosynthesis by Pseudomonas fluorescens biocontrol strains. Appl. Environ. Microbiol. 65:2429-2438.

Haas, D., and Défago, G. 2005. Biological control of soil-borne pathogens by fluorescent pseudomonads. Nature Rev. Microbiol. 3:307-319.

Haas, D., and Keel, C. 2003. Regulation of antibiotic production in rootcolonizing Pseudomonas spp. and relevance for biological control of plant disease. Annu. Rev. Phytopathol. 41:117-153.

Heeb, S., Itoh, Y., Nishijyo, T., Schnider, U., Keel, C., Wade, J., Walsh, U., O'Gara, F., and Haas, D. 2000. Small, stable shuttle vectors based on the minimal pVS1 replicon for use in gram-negative, plant-associated bacteria. Mol. Plant-Microbe Interact. 13:232-237.

Hiementz, P. C. 1986. Principles of coloid and surface chemistry. Marcel Dekker, Inc., New York.

Hommais, F., Krin, E., Laurent-Winter, C., Soutourina, O., Malpertuy, A., Le Caer, J.-P., Danchin, A., and Bertin, P. 2001. Large-scale monitoring of pleiotropic regulation of gene expression by the prokaryotic nucleoid-associated protein, H-NS. Mol. Microbiol. 40:20-36.

Jucker, B. A., Harms, H., and Zehnder, A. J. B. 1998. Polymer interactions between five gram-negative bacteria and glass investigated using LPS micelles and vesicles as model systems. Coll. Surf. B: Biointerf. 11:33-45.
Keel, C., and Défago, G. 1997. Interactions between beneficial soil bacteria and root pathogens: Mechanisms and ecological impact. Pages 2746 in: Multitrophic Interactions in Terrestrial Systems. A. C. Gange and V. K. Brown, eds. Blackwell Science, London.

Keel, C., Schnider, U., Maurhofer, M., Voisard, C., Laville, J., Burger, U., Wirthner, P., Haas, D., and Défago, G. 1992. Suppression of root diseases by Pseudomonas fluorescens CHA0: Importance of the bacterial secondary metabolite 2,4-diacetylphloroglucinol. Mol. Plant-Microbe Interact. 5:4-13.

Keel, C., Weller, D. M., Natsch, A., Défago, G., Cook, R. J., and Thomashow, L. S. 1996. Conservation of the 2,4-diacetylphloroglucinol biosynthesis locus among fluorescent Pseudomonas strains from diverse geographic locations. Appl. Environ. Microbiol. 62:552-563.

Keel, C., Ocurum, Z., Michaux, P., Adrian, M., and Haas, D. 2002. Deleterious impact of a virulent bacteriophage on survival and biocontrol activity of Pseudomonas fluorescens strain CHA0 in natural soil. Mol. Plant-Microbe Interact. 15:567-576.

Koch, B., Jensen, L. E., and Nybroe, O. 2001. A panel of Tn7-based vectors for insertion of the $g f p$ marker gene or for delivery of cloned DNA into gram-negative bacteria at a neutral chromosomal site. J. Microbiol. Meth. 45:187-195.

Kraus, J., and Loper, J. E. 1995. Characterization of a genomic region required for production of the antibiotic pyoluteorin by the biological control agent Pseudomonas fluorescens Pf-5. Appl. Environ. Microbiol. 61:849-854.

Kuiper, I., Lagendijk, E. L., Pickford, R., Derrick, J. P., Lamers, G. E. M., Thomas-Oates, J. E., Lugtenberg, B. J. J., and Bloemberg, G. V. 2004 Characterization of two Pseudomonas putida lipopeptide biosurfactants, putisolvin I and II, which inhibit biofilm formation and break down existing biofilms. Mol. Microbiol. 51:97-113.

Kumar, S., Tamura, K., Jakobsen, I. B., and Nei, M. 2001. MEGA2: Molecular evolutionary genetics analysis software. Bioinformatics 17:1244-1245.

Lugtenberg, B. J. J., Dekkers, L., and Bloemberg, G. V. 2001. Molecular determinants of rhizosphere colonization by Pseudomonas. Annu. Rev. Phytopathol. 39:461-490.

Maurhofer, M., Keel, C., Schnider, U., Voisard, C., Haas, D., and Défago, G. 1992. Influence of enhanced antibiotic production in Pseudomonas fluorescens strain CHA0 on its disease suppressive capacity. Phytopathology 82:190-195.

Maurhofer, M., Keel, C., Haas, D., and Défago, G. 1994. Pyoluteorin production by Pseudomonas fluorescens strain CHA0 is involved in the suppression of Pythium damping-off of cress but not of cucumber. Eur. J. Plant Pathol. 100:221-232.

Maurhofer, M., Keel, C., Haas, D., and Défago, G. 1995. Influence of plant species on disease suppression by Pseudomonas fluorescens strain CHA0 with enhanced antibiotic production. Plant Pathol. 44:40-50.

Maurhofer, M., Baehler, E., Notz, R., Martinez, V., and Keel, C. 2004 Cross talk between 2,4-diacetylphloroglucinol-producing biocontrol pseudomonads on wheat roots. Appl. Environ. Microbiol. 70:19901998

Nelson, K. E., Weinel, C., Paulsen, I. T., Dodson, R. J., Hilbert, H., Martins dos Santos, V. A. P., Fouts, D. E., Gill, S. R., Pop, M., Holmes, M. Brinkac, L., Beanan, M., DeBoy, R. T., S., D., Kolonay, J., Madupu, R., Nelson, W., White, O., Peterson, J., Khouri, H., Hance, I., Lee, P. C., Holtzapple, E., Scanlan, D., Tran, K., Moazzez, A., Utterback, T., Rizzo, M., Lee, K., Kosack, D., Moestl, D., Wedler, H., Lauber, J., Stjepandic, D., Hoheisel, J., Straetz, M., Heim, S., Kiewitz, C., Eisen, J., Timmis, K. N., Düsterhöft, A., Tümmler, B., and Fraser, C. M. 2002. Complete genome sequence and comparative analysis of the metabolically versatile Pseudomonas putida KT2440. Environ. Microbiol. 4:799-808.

Notz, R., Maurhofer, M., Schnider-Keel, U., Duffy, B., Haas, D., and Défago, G. 2001. Biotic factors affecting expression of the 2,4-diacetylphloroglucinol biosynthesis gene phlA in Pseudomonas fluorescens biocontrol strain CHA0 in the rhizosphere. Phytopathology 91:873-881.

Nowak-Thompson, B., Chaney, N., Wing, J. S., Gould, S. J., and Loper, J. E. 1999. Characterization of the pyoluteorin biosynthetic gene cluster of Pseudomonas fluorescens Pf-5. J. Bacteriol. 181:2166-2174.

O'Toole, G. A. and Kolter, R. 1998. Initiation of biofilm formation in Pseudomonas fluorescens WCS365 proceeds via multiple, convergent signaling pathways: A genetic analysis. Mol. Microbiol. 28:449-461

Paulsen, I. T., Press, C. M., Ravel, J., Kobayashi, D. Y., Myers, G. S., Mavrodi, D. V., DeBoy, R. T., Seshadri, R., Ren, Q., Madupu, R., Dodson, R. J., Durkin, A. S., Brinkac, L. M., Daugherty, S. C., Sullivan, S. A., Rosovitz, M. J., Gwinn, M. L., Zhou, L., Schneider, D. J., Cartinhour, S. W., Nelson, W. C., Weidman, J., Watkins, K., Tran, K., Khouri, H., Pierson, E. A., Pierson, L. S., III, Thomashow, L. S., and Loper, J. E. 2005. Complete genome sequence of the plant commensal Pseudomonas fluorescens Pf-5. Nat. Biotechnol. 23:873-878. 
Péchy-Tarr, M., Bottiglieri, M., Mathys, S., Bang Lejbølle, K., SchniderKeel, U., Maurhofer, M., and Keel, C. 2005. RpoN $\left(\sigma^{54}\right)$ controls production of antifungal compounds and biocontrol activity in Pseudomonas fluorescens CHA0. Mol. Plant-Microbe Interact. 18:260-272.

Redman, J. A., Walker, S. L., and Elimelech, M. 2004. Bacterial adhesion and transport in porous media: Role of the secondary energy minimum. Environ. Sci. Technol. 38:1777-1785.

Rescalli, E., Saini, S., Bartocci, C., Rychlewski, L., De Lorenzo, V., and Bretoni, G. 2004. Novel physiological modulation of the $P u$ promoter of TOL plasmid: Negative regulatory role of the TurA protein of Pseudomonas putida in the response to suboptimal growth temperatures. J. Biol. Chem. 279:7777-7784.

Rijnaarts, H. H. M., Norde, W., Bouwer, E. J., Lyklema, J., and Zehnder, A. J. B. 1993. Bacterial adhesion under static and dynamic conditions. Appl. Eviron. Microbiol. 59:3255-3265.

Rijnaarts, H. H. M., Norde, W., Lyklema, J., and Zehnder, A. J. B. 1995. The isolelectric point of bacteria as indicator for the presence of cell surface polymers that inhibit adhesion. Coll. Surf. B Biointerf. 4:191-197.

Rimsky, S. 2004. Structure of the histone-like protein H-NS and its role in regulation and genome superstructure. Curr. Opin. Microbiol. 7:109114.

Rosenthal, R. S., and Rodwell, V. W. 1998. Purification and characterization of the heteromeric transcriptional activator MvaT of the Pseudomonas mevalonii mvaAB operon. Protein Sci. 7:178-184.

Sacherer, P., Defago, G., and Haas, D. 1994. Extracellular protease and phospholipase $\mathrm{C}$ are controlled by the global regulatory gene gacA in the biocontrol strain Pseudomonas fluorescens CHA0. FEMS (Fed. Eur. Microbiol. Soc.) Microbiol. Lett. 116:155-160.

Sambrook, J., and Russell, D. W. 2001 Molecular cloning: A laboratory manual, 3rd edition. Cold Spring Harbor Laboratory Press, Cold Spring Harbor, NY, U.S.A.

Sarniguet, A., Kraus, J., Henkels, M. D., Muehlchen, A. M., and Loper, J. E. 1995. The sigma factor $\sigma^{\mathrm{S}}$ affects antibiotic production and biological control activity of Pseudomonas fluorescens Pf-5. Proc. Natl. Acad. Sci. U.S.A. 92:12255-12259.

Schnider, U., Keel, C., Blumer, C., Troxler, J., Défago, G., and Haas, D. 1995. Amplification of the house-keeping sigma factor in Pseudomonas fluorescens $\mathrm{CHA} 0$ enhances antibiotic production and improves biocontrol abilities. J. Bacteriol. 177:5387-5392.

Schnider-Keel, U., Bang Lejbølle, K., Baehler, E., Haas, D., and Keel, C. 2001. The sigma factor $\mathrm{AlgU}(\mathrm{AlgT})$ controls exopolysaccharide production and tolerance towards desiccation and osmotic stress in the biocontrol agent Pseudomonas fluorescens CHA0. Appl. Environ. Microbiol. 67:5683-5693.

Schnider-Keel, U., Seematter, A., Maurhofer, M., Blumer, C., Duffy, B. Gigot-Bonnefoy, C., Reimmann, C., Notz, R., Défago, G., Haas, D., and Keel, C. 2000 Autoinduction of 2,4-diacetylphloroglucinol biosynthesis in the biocontrol agent Pseudomonas fluorescens $\mathrm{CHA} 0$ and repression by the bacterial metabolites salicylate and pyoluteorin. J. Bacteriol. 182:1215-1225.

Schwyn, B., and Neilands, J. B. 1987. Universal chemical assay for the detection and determination of siderophores. Anal. Biochem. 160:47-56.

Soutourina, O. A., Krin, E., Laurent-Winter, C., Hommais, F., Danchin, A., and Bertin, P. N. 2002. Regulation of bacterial motility in response to low $\mathrm{pH}$ in Escherichia coli: The role of H-NS protein. Microbiology 148:1543-1551.

Stover, C. K., Pham, X. Q., Erwin, A. L., Mizoguchi, S. D., Warrener, P. Hickey, M. J., Brinkman, F. S., Hufnagle, W. O., Kowalik, D. J., Lagrou, M., Garber, R. L., Goltry, L., Tolentino, E., Westbrock-Wadman, S., Yuan, Y., Brody, L. L., Coulter, S. N., Folger, K. R., Kas, A., Larbig, K., Lim, R., Smith, K., Spencer, D., Wong, G. K., Wu, Z., Paulsen, I. T., Reizer, J., Saier, M. H., Hancock, R. E., Lory, S., and Olson, M. V.
2000. Complete genome sequence of Pseudomonas aeruginosa PAO1, an opportunistic pathogen. Nature 406:959-964.

Tendeng, C., and Bertin, P. N. 2003. H-NS in gram-negative bacteria: A family of multifaceted proteins. Trends Microbiol. 11:511-518.

Tendeng, C., Soutourina, O. A., Danchin, A., and Bertin, P. N. 2003. MvaT proteins in Pseudomonas spp.: A novel class of H-NS-like proteins. Microbiology 149:3047-3050.

Thompson, J. D., Higgins, D. G., and Gibson, T. J. 1994. CLUSTAL W: Improving the sensitivity of progressive multiple sequence alignment through sequence weighting, positions-specific gap penalties and weight matrix choice. Nucl. Acids Res. 22:4673-4680.

Vallet, I., Diggle, S. P., Stacey, R. E., Camara, M., Ventre, I., Lory, S., Lazdunski, A., Williams, P., and Filloux, A. 2004. Biofilm formation in Pseudomonas aeruginosa: Fimbrial cup gene clusters are controlled by the transcriptional regulator MvaT. J. Bacteriol. 186:2880-2890.

Vallet-Gely, I., Donovan, K. E., Fang, R., Joung, J. K., and Dove, S. L. 2005. Repression of phase-variable cup gene expression by H-NS-like proteins in Pseudomonas aeruginosa. Proc. Natl. Acad. Sci. U.S.A. 102:11082-11087.

Valverde, C., Lindell, M., Wagner, E. G. H., and Haas, D. 2004. A repeated GGA motif is critical for the activity and stability of the riboregulator RsmY of Pseudomonas fluorescens. J. Biol. Chem. 279:25066-25074.

Van Loon, L. C., and Bakker, P. A. H. M. 2004. Signaling in rhizobacteriaplant interactions. Pages 287-330 in: Ecological Studies, Vol. 168, Root Ecology. J. De Kroon and E. J. W. Visser, eds. Springer Verlag, Berlin.

van Loosdrecht, M. C. M., Lyklema, J., Norde, W., Schraa, G., and Zehnder, A. J. B. 1987. Electrophoretic mobility and hydrophobicity as a measure to predict the initial steps of bacterial adhesion. Appl. Environ. Microbiol. 53:1898-1901.

van Oss, C. J. 1994. Interfacial forces in aqueous media. Marcel Dekker, New York.

Vieira, J., and Messing, J. 1991. New pUC-derived cloning vectors with different selectable markers and DNA replication origins. Gene 100:189-194

Voisard, C., Keel, C., Haas, D., and Défago, G. 1989. Cyanide production by Pseudomonas fluorescens helps suppress black root rot of tobacco under gnotobiotic conditions. EMBO (Eur. Mol. Biol. Organ.) J. 8:351-358.

Voisard, C., Bull, C., Keel, C., Laville, J., Maurhofer, M., Schnider, U. Défago, G., and Haas, D. 1994. Biocontrol of root diseases by Pseudomonas fluorescens CHA0: Current concepts and experimental approaches. Pages 67-89 in: Molecular Ecology of Rhizosphere Microorganisms. F. O'Gara, D. Dowling and B. Boesten, eds. VCH Publishers, Weinheim, Germany.

Westfall, L. W., Luna, A. M., San Francisco, M., Diggle, S. P., Worrall, K. E. Williams, P., Camara, M., and Hamood, A. N. 2004. The Pseudomonas aeruginosa global regulator MvaT specifically binds to the $p t x S$ upstream region and enhances ptxS expression. Microbiology 150:3797-806.

\section{AUTHOR-RECOMMENDED INTERNET RESOURCES}

European Molecular Biology Open Software Suite (EMBOSS) website: www.ch.embnet.org/EMBOSS/index.html

Joint Genome Institute (JGI) Microbial Genomics website: genome.jgi-psf.org/mic_home.html

Massachusetts General Hospital, Harvard Medical School ParaBioSys website: pga.mgh.harvard.edu

Network Protein Sequence Analysis website: npsa-pbil.ibcp.fr

Sanger Institute's Pseudomonas fluorescens SBW25 website: www.sanger.ac.uk/Projects/P fluorescens

University of Birmingham PseudoDB website: pseudo.bham.ac.uk/genome 